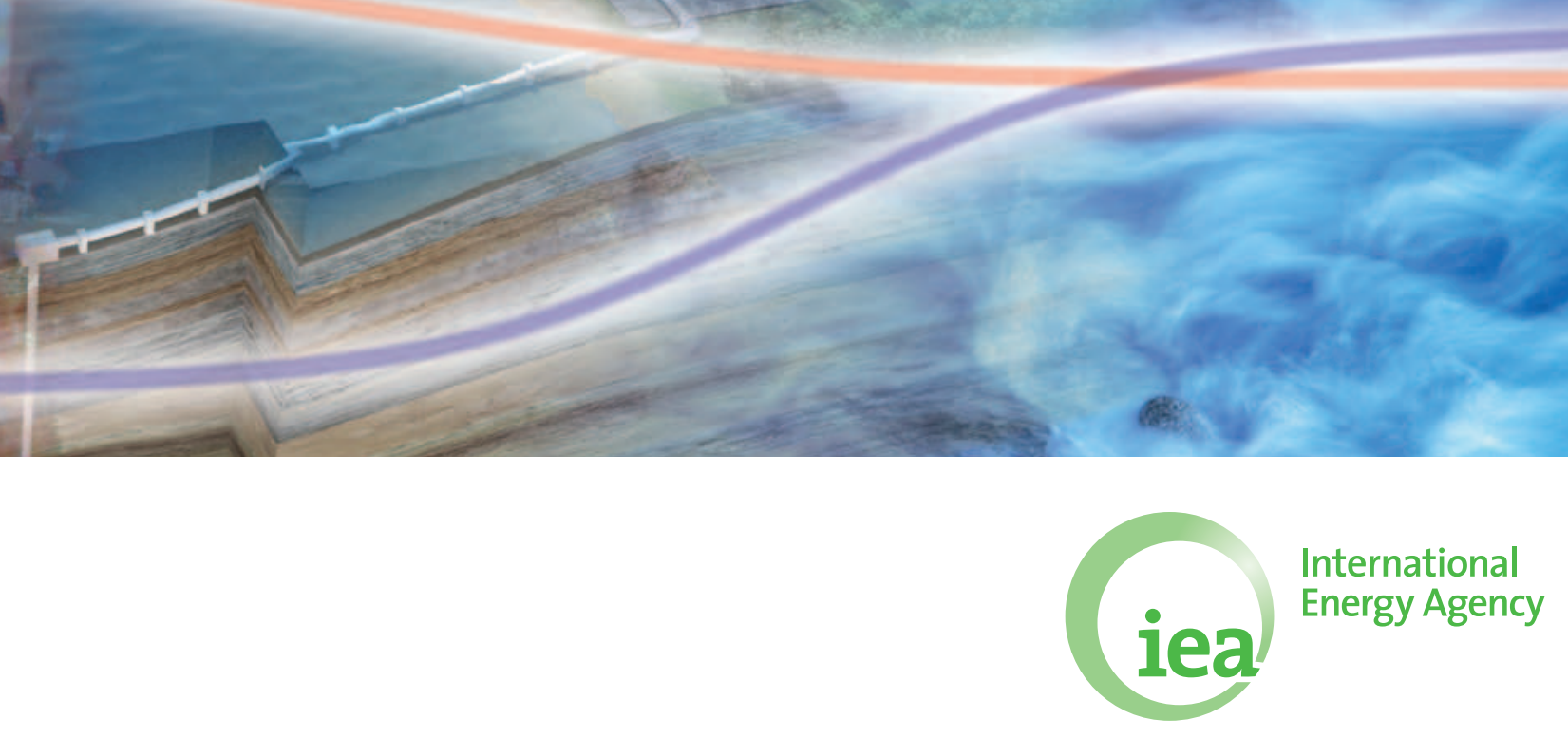

\title{
A POLICY STRATEGY FOR CARBON CAPTURE AND STORAGE
}





\section{A POLICY STRATEGY FOR CARBON CAPTURE AND STORAGE}


The International Energy Agency (IEA), an autonomous agency, was established in November 1974. Its primary mandate was - and is - two-fold: to promote energy security amongst its member countries through collective response to physical disruptions in oil supply, and provide authoritative research and analysis on ways to ensure reliable, affordable and clean energy for its 28 member countries and beyond. The IEA carries out a comprehensive programme of energy co-operation among its member countries, each of which is obliged to hold oil stocks equivalent to 90 days of its net imports. The Agency's aims include the following objectives:

- Secure member countries' access to reliable and ample supplies of all forms of energy; in particular, through maintaining effective emergency response capabilities in case of oil supply disruptions.

- Promote sustainable energy policies that spur economic growth and environmental protection in a global context - particularly in terms of reducing greenhouse-gas emissions that contribute to climate change.

- Improve transparency of international markets through collection and analysis of energy data.

- Support global collaboration on energy technology to secure future energy supplies and mitigate their environmental impact, including through improved energy

efficiency and development and deployment of low-carbon technologies.

- Find solutions to global energy challenges through engagement and dialogue with non-member countries, industry, international organisations and other stakeholders.

IEA member countries:

\section{Czech Republic}

\section{Denmark}

Finland

France

Germany

\section{Greece}

Hungary

Ireland

Italy

Japan

Korea (Republic of)

Luxembourg

Netherlands

New Zealand

Norway

Poland

Portugal

(c) OECD/IEA, 2012

\section{International Energy Agency}

9 rue de la Fédération

75739 Paris Cedex 15, France

www.iea.org

Please note that this publication

is subject to specific restrictions

that limit its use and distribution.

The terms and conditions are available

online at www.iea.org/about/copyright.asp

Slovak Republic

Spain

Sweden

Switzerland

Turkey

United States
United Kingdom

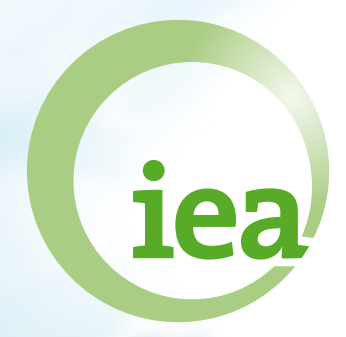

International Energy Agency

\author{
The European Commission \\ also participates in \\ the work of the IEA
}




\section{Table of Contents}

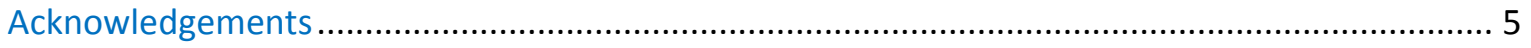

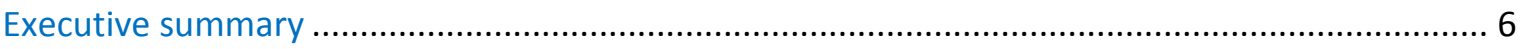

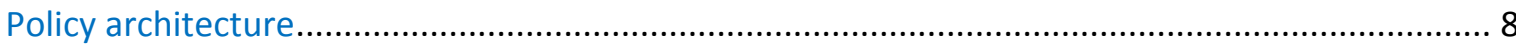

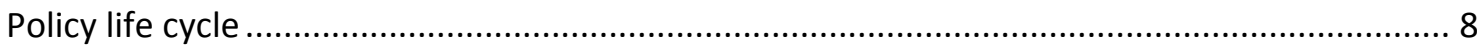

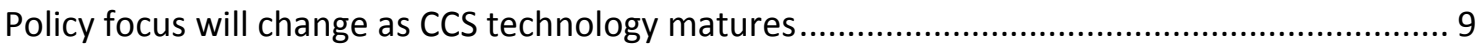

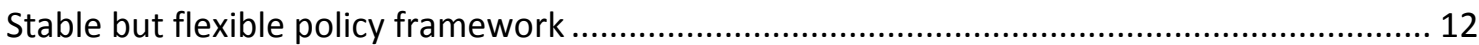

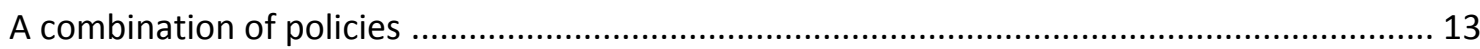

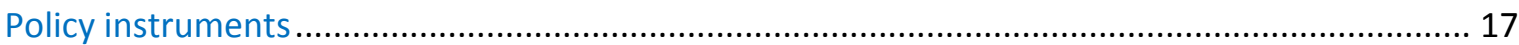

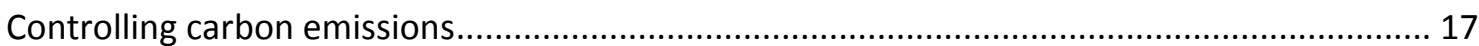

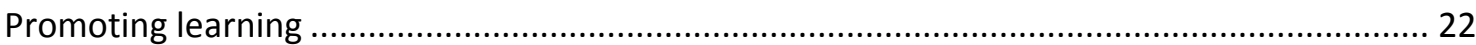

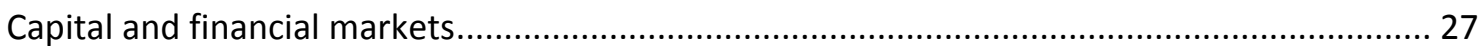

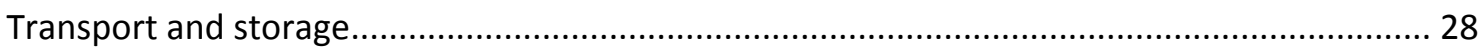

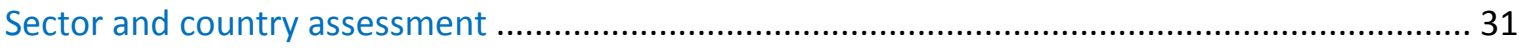

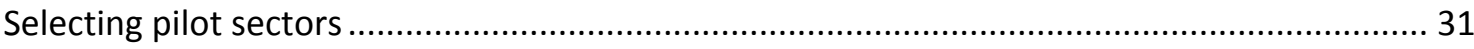

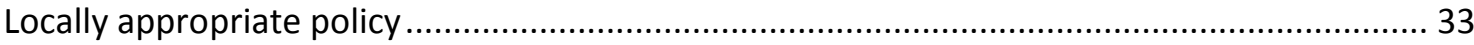

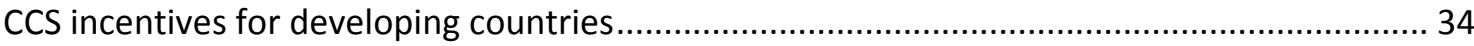

BECCS

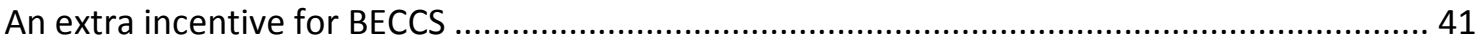

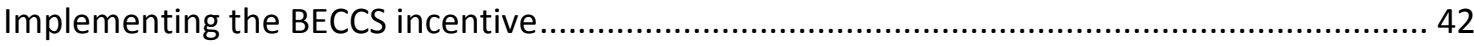

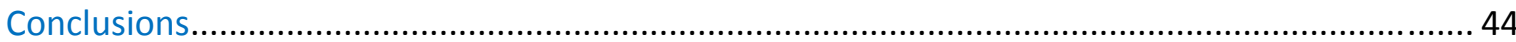

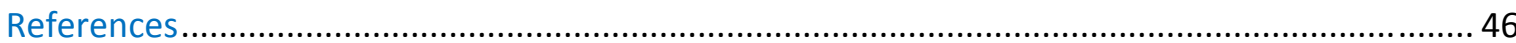

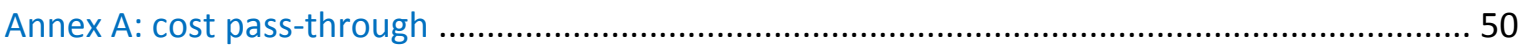

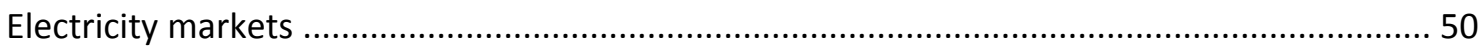

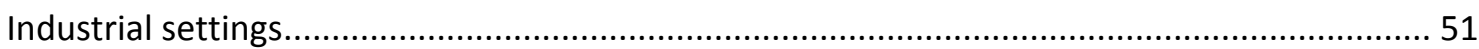

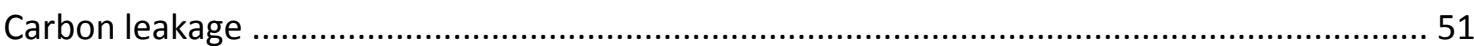




\section{List of figures}

Figure 1 Current carbon prices from the EU Emissions Trading Scheme or the

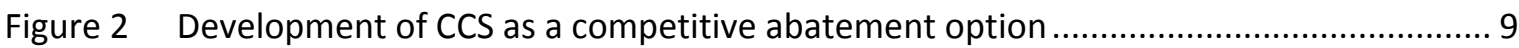

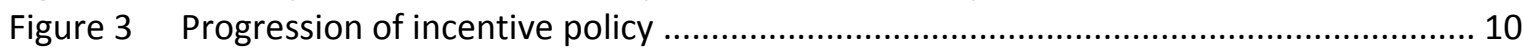

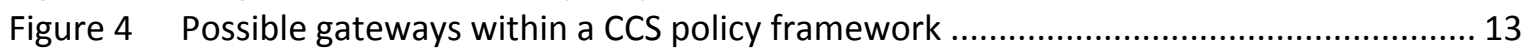

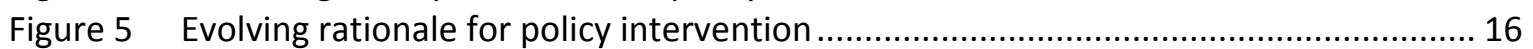

Figure 6 Comparing power, cement, steel, natural gas processing and refineries sectors in

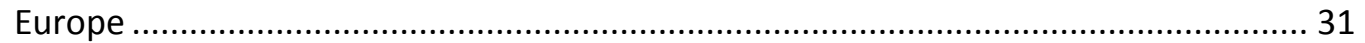

Figure 7 Comparing power, cement, steel, natural gas processing and refineries sectors in the United States.

Figure 8 Analysis identifying developed countries most motivated to support CCS in the developing world.

Figure 9 Analysis to identify developing countries with greatest strategic interested in

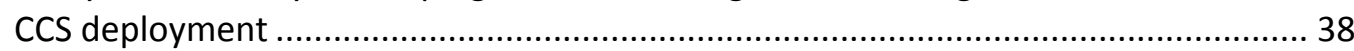

Figure 10 BECCS lifecycle emissions can be recognised at one of three points............................ 42

Figure 11 Factors influencing cost pass-through in different markets ....................................... 54

\section{List of boxes}

Box 1 An example of adverse policy interaction 15

Box 2 A combination of CCS initiatives from recent UK electricity market reform proposals .. 16

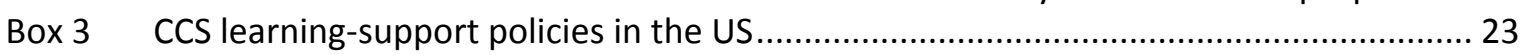

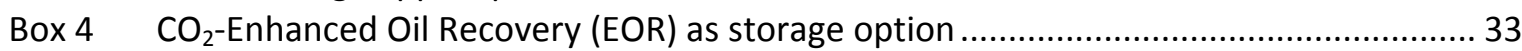

Box 5 IFIs could support CCS in developing countries in a number of ways ............................. 39

\section{List of tables}

Table 1 An assessment of instruments to control carbon emissions 21

Table 2 Policy tools used to tackle knowledge market failures and promote learning.............. 26

Table 3 Policies used to tackle capital and financial market failures........................................... 28

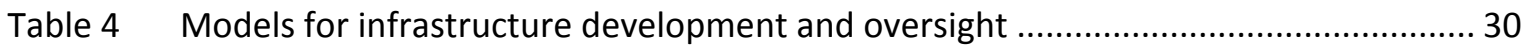

Table 5 Comparing lifecycle emissions of conventional CCS and BECCS ................................ 41

Table 6 Advantages and disadvantages of BECCS incentive options ...................................... 43 


\section{Acknowledgements}

This report drew from the expertise of many individuals both inside and outside the IEA. Special thanks go to our consultants Robin Smale, John Ward and Max Krahe at Vivid Economics for expert advice and for developing the draft text. Dr. Adam Brown, Anselm Eisentraut, Christina Hood, Ellina Levina, Juho Lipponen, and Dr. Matthias Finkenrath from the IEA Secretariat provided numerous suggestions on various versions of the entire manuscript, while the section on BECCS benefited from input from Dr. Sabine Fuss and Dr. Florian Kraxner, International Institute for Applied Systems Analysis. Lastly, thanks should also go to the following peer reviewers for making time available to read the manuscript and for providing constructive comments: Dr. Ottmar Edenhofer, Dr. Christian Flachsland, Dr. Christoph von Stechow, Matthias Kalkuhl, Potsdam Institute for Climate Impact Research; Natalia Kulichenko, the World Bank; Dr. Warwick McKibbin, Australian National University; Dr. Jose Moreira, Brazilian Reference Center on Biomass; and Dr. John Parsons, Massachusetts Institute of Technology.

For more information on this document, contact:

Dr. Wolf Heidug, IEA Secretariat

Tel. +33140576512

Email: Wolf.HEIDUG@iea.org 


\section{Executive summary}

This guide for policy makers aims to assist those involved in designing national and international policy related to carbon capture and storage (CCS). Covering both conventional fossil-fuel CCS and bioenergy with CCS (BECCS), it explores development of CCS from its early pilot and

Page | 6 demonstration project stages through to wide-scale deployment of the technology. The report concentrates on the economic and political economy perspective, leaving legal, safety, environmental and regulatory issues to be addressed by other analysis.

\section{Policy support critical to tap CCS potential}

The IEA's Energy Technology Perspectives (IEA, 2010a) indicates that CCS is an essential part of the portfolio of technologies needed to achieve substantial global greenhouse gas (GHG) emissions reduction in the most cost-effective manner. The technology could - if governments commit to specific policies - account for nearly one-fifth of the emissions reduction required to cut GHG emissions from energy use in half by 2050. The scale of potential future deployment of CCS is enormous, spanning manufacturing, power generation and hydrocarbon extraction worldwide.

Despite this huge potential, there remains considerable doubt as to the precise role CCS will play. Deploying CCS requires policy action; it is not something that the market will do on its own. CCS policy will have to address the creation of new markets, market barriers and failures, and promotion and regulation of infrastructure. With such high stakes, the quality of policy matters a great deal - at two levels: overall policy architecture and selection of policy instruments.

\section{Policy architecture, policy instruments}

Policy architecture refers to the overall policy framework - the vision and main structural elements and how they fit together. It encompasses a range of policy instruments, with each chosen instrument designed to respond to a particular policy objective over time. Together these instruments can comprehensively improve the conditions for uptake of CCS technology in a way that suits the market environment.

The appropriate policy for CCS evolves as the technology matures. The policy moves from technology-specific support, which explicitly targets the development of CCS as a commercial activity, to technology-neutral support, which allows deployment of CCS when it is most cost effective among other abatement opportunities. Policy may also adapt from supporting both CCS investment and operation to an emphasis on CCS operation; from an approach where the public and private sector share in the costs and risks of CCS development to one where costs and risks are mainly borne by the private sector; and from an approach where CCS is incentivised by providing subsidies to an approach where it is incentivised by pricing emissions.

\section{Policy to address sectoral and national factors}

Many challenges associated with CCS deployment are common to all sectors, including site selection, monitoring and project approvals. Sectors with low trade exposure, low CCS costs and high carbon dioxide $\left(\mathrm{CO}_{2}\right)$ emissions (such as processing of natural gas and the power sector in some regions) offer good opportunities to pilot CCS projects and prioritise learning. 
Potential benefits of CCS are greater for countries that are coal and gas producers, consumers, or those that anticipate chronic effects from climate change. Developed countries fulfilling these criteria include Australia and the United States. In the short and medium term, learning benefits are most important. The focus should be on demonstration projects that provide the best opportunities for learning at the least net cost. This supports the argument in favour of CCS projects in areas where there is a potential commercial market for the captured $\mathrm{CO}_{2}$ (e.g. for enhanced oil recovery) or in developing countries that stand to profit from CCS. Such a strategy could help lower support cost for the first generation of CCS plants while avoiding duplication of effort.

\section{Added incentive for BECCS}

Among the many applications of CCS, BECCS is of particular interest because it offers the potential not only to reduce emissions, but also to actually remove $\mathrm{CO}_{2}$ from the atmosphere, thereby reducing atmospheric GHG concentrations and directly counteracting one of the main drivers of climate change. An additional incentive targeted specifically at BECCS may help to realise its potential, but it would only be fully effective in combination with an update of accounting policy and methods to account for emissions from land-use change. 


\section{Policy architecture}

Incentive policies for deployment of CCS initially aim to overcome technical and commercial barriers and support technology learning. If CCS technology progresses as intended, the policy focus will gradually move to support mass deployment through incentives to reduce emissions -

Page | 8 where it is cost-effective to do so. Timing of this change in policy focus is difficult to predict, because it will depend on how CCS and alternative technologies mature. However, a stable policy framework with clearly defined break points or "gateways" can offer flexibility to government and some certainty to investors. Effective support for CCS calls for a combination of policies, where each policy addresses a separate dimension of market failure.

\section{Policy life cycle}

\section{CCS technology will change substantially over the next 40 years}

CCS is a high cost abatement option and will remain so in the short-term. It is technically immature (at least in terms of integrating capture, transport and storage in full-scale projects) and, unlike renewable energy and energy efficiency, it does not generate revenues if there is no carbon price or a commercial market for the captured $\mathrm{CO}_{2}$ for enhanced oil recovery. Current carbon prices are well below CCS costs (Figure 1). This is because current short-term emissions targets can be met without the use of CCS.

Figure 1 Current carbon prices from the EU Emissions Trading Scheme or the Clean Development Mechanism

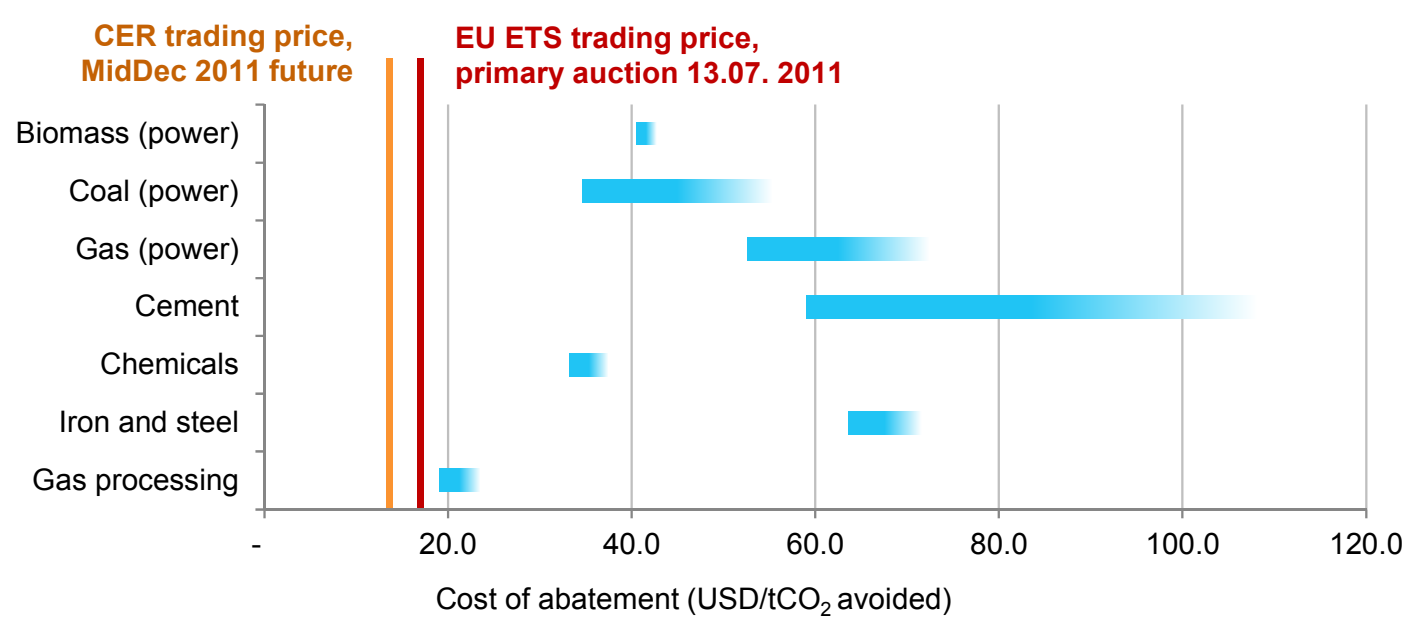

Source: IEA (2009), EEX (prices taken 20 July 2011) and Vivid Economics.

The private sector is unlikely to invest in CCS because the cost of abatement is higher than current carbon prices. The private sector's willingness to invest may improve over time, though at different rates in different sectors as CCS becomes a more competitive abatement option (Figure 2). Research and development, and experience gained from demonstration projects will lower costs, while rising carbon prices will boost revenues. The IEA BLUE Map scenario (IEA, 2010a) shows how it might be possible to reduce by $2050 \mathrm{CO}_{2}$ emissions from energy use to $50 \%$ of their 2005 level. The scenario indicates that $19 \%$ of total emissions reductions could come from CCS. 


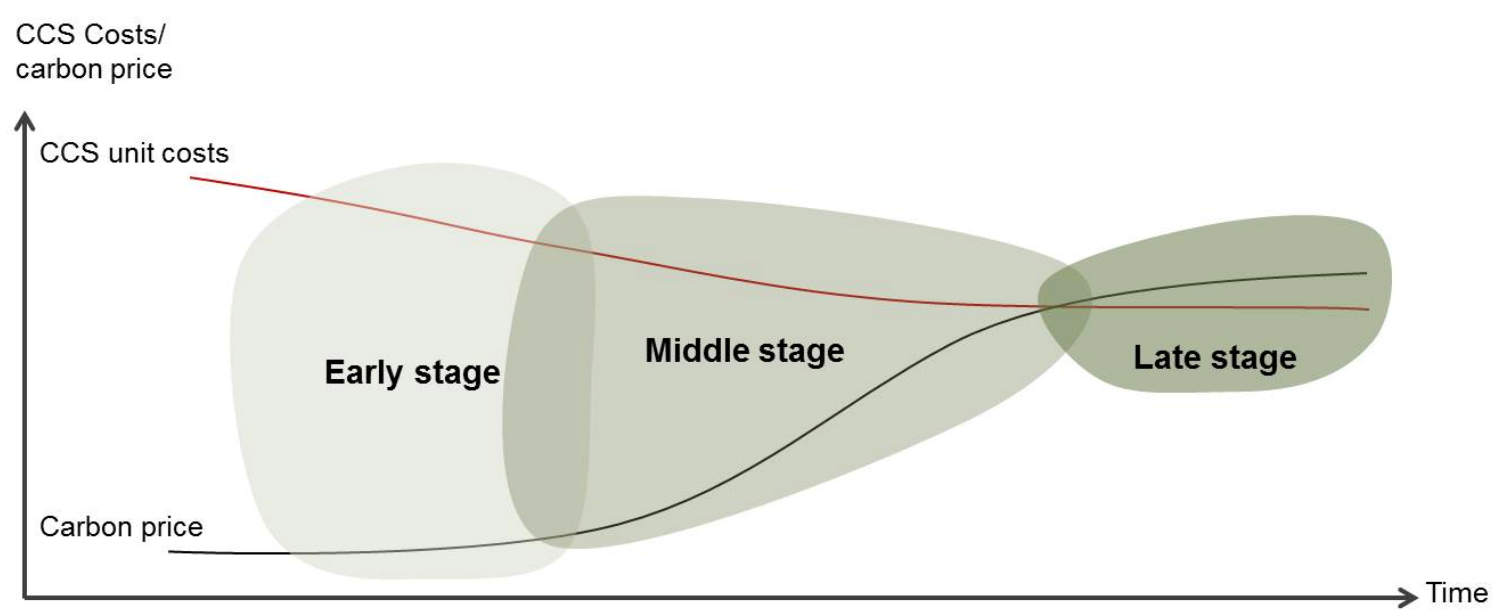

\section{Policy focus will change as CCS technology matures}

Initially, incentive policy will focus on trials of CCS at a commercial scale, seeking information and cost reductions to make it possible to deploy CCS at reasonable scale and cost. The policy goal at this point is not to make emissions reductions for their own sake, but rather to advance CCS technology and establish commercial arrangements between capture, networks and storage. Practical examples of such policies are the various demonstration programmes launched in the European Union (EU), North America and Australia.

Over time, CCS technology will mature and investors will become more familiar with it. As emission reduction targets become more demanding, firms will come to understand where the best opportunities lie. Policy makers may either direct emissions savings where they believe them to be most cost-effective or simply let the market decide where to invest.

The policy choices fall under four broad themes ${ }^{1}$ and the policy approach is likely to shift over time (Figure 3):

- Funding: incentives for capital deployment or for operations;

- Costs and risks: borne by the public sector or the private sector;

- Subsidies/penalties: subsidising abatement or penalising emissions; and

- Technology support: targeting CCS-specific incentives or technology-neutral incentives.

\footnotetext{
${ }^{1}$ Public support for research and development of CCS will also be crucial. However, as this report focuses on incentive mechanisms to encourage widespread deployment of CCS, it does not explore policies or incentives relating to R\&D.
} 
Figure 3 Progression of incentive policy

\section{Early stage}

Page | 10

1

Supporting capital deployment and operations

2

Costs and risks shared by public and private sector

3 Subsidising abatement

$4 \quad$ CCS-specific support
As technology matures

Greater willingness to invest by capital markets

Reduced learning spill-overs and better knowledge of risks

Polluter pays

Achieving least-cost abatement

\section{Late stage}

Incentivising operations

Costs and risks mainly borne by private sector

Penalising emissions

Technology-agnostic policy

\section{From capital to operating incentives}

The early stages of CCS will require support for both capital deployment and the operation of capture units, networks and storage. Faced with a combination of technology risk, immature regulatory and policy frameworks and low or absent market revenues, capital providers will be reluctant to commit substantial sums. Investment support will be necessary, in the form of grants and/or provision of debt or equity capital, as will operating support for CCS (i.e. incentive mechanisms to provide additional revenue for each unit of output where a CCS unit is operational). Plants fitted with CCS will have higher operating costs, but often no additional revenue. Without further policy support for operations, the asset will not be used. ${ }^{2}$

Over time, risks surrounding the technology will diminish and the regulatory and policy framework will become better established and understood. As returns over the lifetime of the asset are substantiated, investors will be more willing to commit funds without capital support. If expectations are realised, capital support can decline and make way for a greater emphasis on operating support.

\section{From public funding to private incentives}

During the early years of CCS support mechanisms, the burden is borne by the taxpayer rather than the private sector (either firms or consumers). At this initial stage, government involvement can facilitate learning opportunities, offering potentially greater benefits to society than by leaving information dissemination to private firms. It can also promote co-ordination between firms, which will facilitate more efficient infrastructure development. Public support is particularly valuable where firms compete internationally and CCS is introduced asymmetrically, which could otherwise lead to adverse effects on trade of goods produced by plants where CCS is fitted.

Public funding for CCS projects is already in place in a number of countries, including Australia, Canada, China, Korea, Japan, Norway, the United States, and in the EU and some EU member states. In total, approximately USD 23.5 billion has been made available to support large-scale demonstration projects (GCCSI, 2011).

\footnotetext{
${ }^{2}$ Such support is less likely to be required where CCS is used for enhanced oil recovery (EOR), as the use of CCS generates a revenue stream from the additional oil extracted.
} 
Over time, tougher emissions targets will translate into higher compliance costs and make it more important for policy to stimulate the most cost-effective forms of abatement. As the volume of abatement generated by CCS increases, support through subsidies is likely to become too costly; and as more countries deploy CCS, trade-exposed sectors will warrant and require less protection. This situation will favour policies that leave both costs and risks with the private sector and use market mechanisms to allocate resources.

When costs and risks are borne by the private sector, market structure and demand conditions determine whether firms can pass on additional costs to consumers. In general, when a sector is less exposed to trade and the cost increase is more comprehensive and uniform across firms, a greater proportion of cost can be passed on to consumers. ${ }^{3}$

\section{From subsidising abatement to penalising emissions}

In the early phases of deployment, the key aim of incentive policies is to expand knowledge of how to deploy CCS technology, in order to identify successful technologies and reduce costs. Such early projects generate information on viability and cost reduction that is valuable to society as a whole, but may not be commercially useful to those undertaking the investment. Subsidies and quantity mandates may be appropriate to encourage commercial firms to invest more than they otherwise would.

When the technology is immature it is not credible to force emissions reduction through high carbon prices. ${ }^{4}$ As learning progresses, the key aim of CCS policy will be directed towards providing incentives for emissions reduction. Then penalties may suffice to stimulate more costeffective CCS. As the volume of CCS-generated abatement grows, reducing support through subsidies will ease pressure on public budgets. In addition, commercial opportunities for using captured $\mathrm{CO}_{2}$ are likely to expand in several markets, further reducing the requirement for public subsidies.

\section{From technology-specific to technology-neutral policies}

Early objectives of CCS incentive policy are to promote the technology, to determine its technical viability, and to demonstrate that it is an affordable option when deeper emission cuts are required. These objectives require policy instruments explicitly targeted at CCS.

Once these three objectives are achieved, the need for technology-specific instruments subsides. The main aim then becomes abatement at lowest possible cost. This is best achieved through a technology-neutral instrument (applying across all abatement technologies), which leaves the market to select the most cost-effective abatement options.

\footnotetext{
${ }^{3}$ See Annex A for a detailed discussion of cost pass-through.

${ }^{4}$ This does not mean that there are not good reasons for introducing carbon prices within an economy in the near term, nor that such carbon prices would not help in the early deployment of CCS in countries where there are carbon prices. It suggests, however, that support for CCS in the short term might not be best achieved through incentives that focus only on penalising emissions.
} 


\section{Stable but flexible policy framework}

\section{Policy credibility encourages investment}

Because of the uncertainty of CCS costs and performance and opportunities offered by other technologies, policy makers value flexibility in incentive policy. However, investors respond strongly to perceived levels of policy commitment. They are particularly sensitive to policy risk when assets (such as CCS) are long-lived and heavily dependent on policy support (Hamilton, 2009).

A potential solution is to set policy within a stable framework, so that the broad architecture and rules of policy evolution are certain. This may lead to lower costs of finance, greater research and development expenditure and more effective infrastructure planning and coordination.

\section{Benefits to firms and government}

Within a stable framework, breakpoints or "policy gateways" can provide the flexibility required. They comprise three components:

- the criteria defining when or if policy moves to the next stage;

- the policies within each stage; and

- an outline of how government will react if gateways are missed.

Gateways can be used to link commitment of government and private resources to achieving certain targets (such as performance thresholds). This allows government to commit funds without the risk of overstretching its resources or imposing poor value-for-money obligations on others. In a scenario in which learning benefits turn out to be small, for instance, policy gateways would allow for cost control without reneging on earlier assurances. For firms, this greater policy commitment may reduce policy risk and ease financing costs by reducing the risk of asset stranding.

\section{How gateways work}

Many different types of gateways could be put in place within a CCS policy framework (Figure 4). In a first policy phase, for example, public capital grants and operating subsidies deliver a sufficient number of projects to test efficacy of the technology. Structures are set up to ensure collaboration and knowledge sharing between the parties to maximise learning benefits. After an initial operating period of some years, policy might switch to the next phase, provided that certain criteria have been met, probably relating to technological efficacy or the development of commercially competitive uses for $\mathrm{CO}_{2}$ in the local market.

A second phase could be a period of larger scale deployment where wider deployment is tried in at least one sector, even if CCS costs cannot be covered by a carbon price alone. Widespread deployment, even in one sector, is unlikely to be feasible through public grants, so the emphasis would switch to private financing with implicit subsidies. These subsidies could take the form of some kind of quantity commitment, either made by government (such as $\mathrm{CO}_{2}$ contracts) or imposed on the private sector (such as portfolio standards). Such quantity commitment could help fuel the development of commercial uses by guaranteeing a low-cost supply of $\mathrm{CO}_{2}$. Without international co-ordination, such subsidy-based policy would be difficult in sectors that are significantly trade exposed, but it would reduce risk for investors and provide the supply chain 
with confidence about magnitude and timing of investments - overcoming some of the key risks faced by these players. Policy would evolve beyond this phase only if CCS costs fall below a predefined threshold.

During the second phase, the policy might extend to infrastructure, setting out arrangements for network development and storage. It might establish codes of practice, liability regimes, rights of access and franchises, as well as commercial arrangements and protections against the failure of the network or storage operator.

If CCS technology becomes fully proven at commercial scale, and the supply chain matures, then a third phase could follow in which CCS is stimulated by a price instrument wherever it is a costeffective solution. This might be achieved through a stable economy-wide carbon price, but narrower, sectoral approaches might also be used. In this phase, long-term planning of infrastructure development might be appropriate, to build greater interconnection and resilience.

What happens if the criteria are not satisfied? If the first gateway is missed, then government may wish to reallocate public support to other technologies that show more promise. If the scaleup proves unsuccessful and the second gateway is missed, the government could continue with a moderate carbon price, accepting that it may not lead to CCS deployment, if alternative technologies are coming forward. In the event that other technology options are not available, there will need to be a continued focus on CCS development even in the face of higher-thanexpected costs. This might be pursued by continuing CCS-specific support measures.

Figure 4 Possible gateways within a CCS policy framework

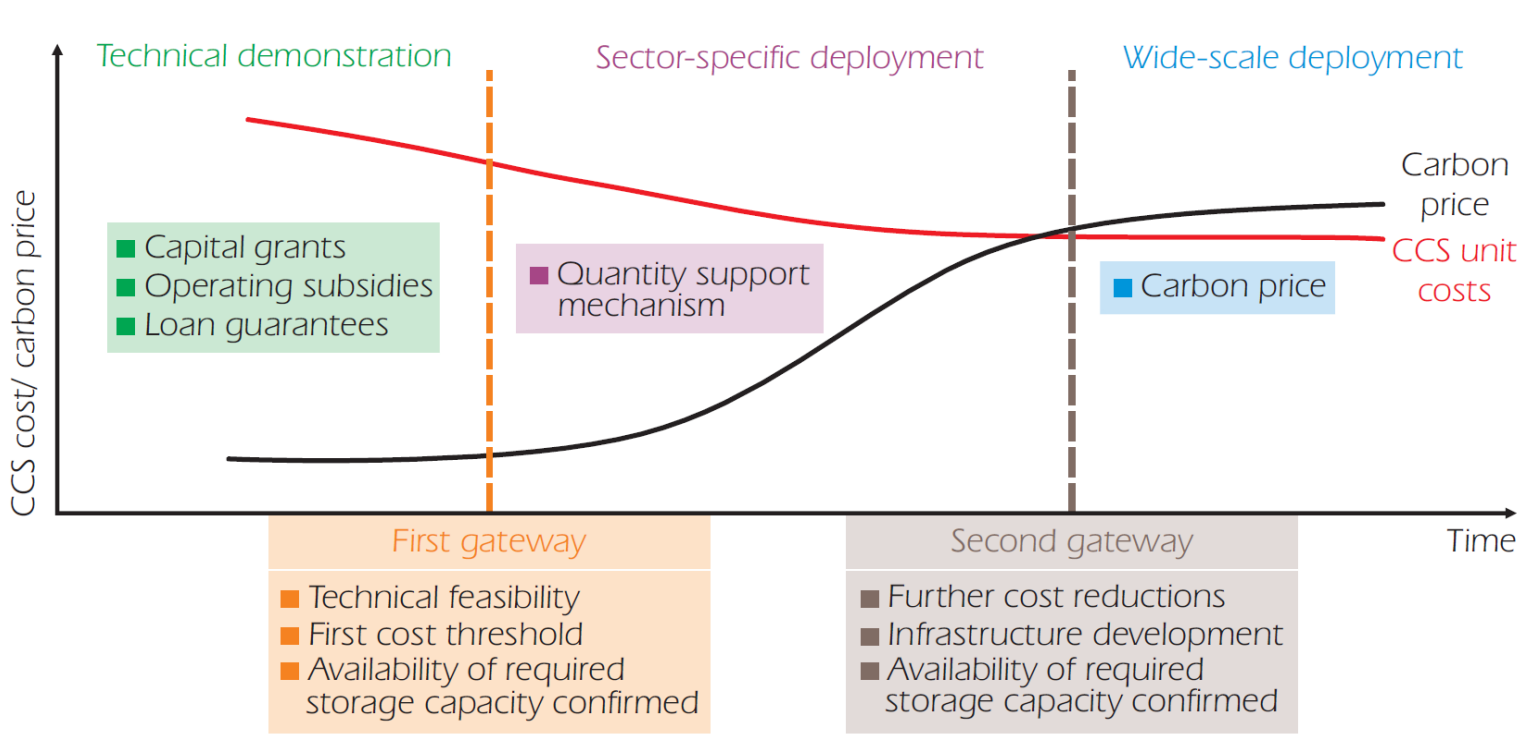

\section{A combination of policies}

\section{Five reasons to intervene}

Five factors may justify policy intervention in markets where CCS could be deployed: externality, public good, imperfect competition, information asymmetry and imperfect information, and complementary markets. 
- Externality: When a firm's action causes impacts on others which it fails to take into account. A classic example is the release of too much $\mathrm{CO}_{2}$ from fossil fuel combustion or natural gas extraction. Another example is the benefit members of a network receive when new members join, boosting economies of scale.

- Public good: When the producer of a good or service cannot prevent others from consuming it and the good is not used up in the process of consumption. The creation of knowledge and innovation relating to CCS has some of these characteristics. This knowledge may be created during a period of research and development or demonstration (where the explicit intention is to better understand the technology) or during a subsequent, early deployment phase. The main focus of this report is on incentives for deployment, and so the latter case is more relevant here. In either case, without intervention, the knowledge is under-produced. It is helpful to distinguish between learning about the efficacy of different sorts of technology across the valuechain (i.e. which technologies work best, or the extent to which there are problems with leakage in different sorts of storage sites), which has been labelled as "learning from diversity" (Newbery et al., 2009), and the knowledge obtained by replicating the same production process many times in a way that allows costs to be reduced (conventional "learning-by-doing"). Given that CCS requires large, discrete investments, learning from diversity may be most important.

- Imperfect competition: $:^{5}$ Where there are a small number of large firms in a market, they may have the power to affect prices through how much output they choose to supply. In $\mathrm{CO}_{2}$ pipe networks, for example, one firm may be unwilling to offer access to its network to other firms on fair and reasonable (i.e. cost-reflective) terms. Similar concerns might also exist in relation to access to storage capacity. The consequence could be a network that is built too small in extent and capacity, with restricted access to pipeline and storage and unreasonably high prices.

- Information asymmetry and imperfect information: When one person holds more information than another, or when information is not known, the market will not allocate resources in an efficient way. This can happen both in product and capital markets. It can lead to managers not behaving in the best interests of shareholders and having their capital budgets restricted, or to customers receiving poor quality products. Information about CCS costs and performance is likely to be unequally distributed, making capital providers unwilling to provide finance if they are unable to discern good projects from bad projects. This could hold back investment in good projects.

- Complementary markets: When one firm depends upon another to get its goods to market, and coordination in output planning is imperfect, the system may undersupply capacity. Examples are $\mathrm{CO}_{2}$ pipelines, storage sites and capture plant, which together form the $\mathrm{CO}_{2}$ capture and storage system. If these parts of the vertical chain are under different ownership, investors in $\mathrm{CO}_{2}$ pipelines, for example, may be unwilling to commit funds as the returns to their investments will depend on potentially unpredictable decisions made by those investing in capture units and storage space. Investors in capture and storage face the converse situation.

To achieve the best possible outcome, all these factors would have to be addressed. However, interventions can create their own distortions or may be designed in such a way that they do not

\footnotetext{
${ }^{5}$ Problems of imperfect competition are not addressed in this report as these are found throughout the economy, necessitating a generic response in the form of regulation by competition authorities.
} 
correct the market failure as anticipated. It is crucial to minimise these policy failures when choosing whether and/or how to intervene.

\section{Separate policy instruments for each market problem}

While market failures justify policy intervention, it is possible that solving one problem may create another. This is especially likely if the policy is poorly designed. One of the principles of good policy design is to appoint a separate policy instrument to tackle each market problem. For CCS, this means instruments to address each of the five factors identified. Using more than one instrument towards the same end may have unintended consequences (Box 1).

Box 1 An example of adverse policy interaction

An emissions cap and trade scheme and a feed-in tariff both support renewable power. The reduction in emissions brought forward by a feed-in tariff does not reduce total emissions, because the total cap on emissions does not adjust. Instead, the reduction in emissions from the expansion of renewable power causes emissions allowance prices to fall, causing a rise in emissions elsewhere in the economy (Fankhauser, Hepburn and Park, 2011). Seebreghts et al. (2010) explicitly note that a similar risk might arise from the support of CCS. This could be accounted for, in the medium to longer term, by adjusting the cap to take account of the emission reductions achieved by other policies. The correct approach is to take account of interactions when designing policies.

Fischer and Newell (2008) find that multiple policies - each aimed at a separate market failure reduce emissions more cost-effectively than a single policy in isolation, and Philibert (2011) broadly concurs. The conclusion for policymakers is that it is appropriate to stimulate CCS using a combination of policy instruments at any one time, and to make a careful exposition and justification of what market failure is tackled by each instrument and why this is not corrected by the other interventions in support of CCS. Recent UK electricity market reform proposals include such a combination of policy instruments (Box 2). 
Box 2 A combination of CCS initiatives from recent UK electricity market reform proposals

The UK Department for Energy and Climate Change (DECC) has recently proposed a combination of instruments to achieve decarbonisation and headroom in power generation capacity. In addition to GBP 1 billion provided to the first CCS demonstration project, and further funding for another one to three CCS projects, the proposals include the following:

(a) an emission performance standard (EPS), set so that no new coal-fired power stations are built without CCS (DECC, 2011a);

(b) a carbon price floor (CPF), intended to reduce investment uncertainty and strengthen the incentive for low carbon electricity generation;

(c) a system of feed-in tariffs (FITs) combined with contract-for-differences (CfD). This in effect guarantees the price received by the generators if the wholesale power price is below an agreed level;

(d) a capacity mechanism, to ensure headroom in generation capacity.

As a set of multiple instruments aimed at multiple objectives, these proposals reflect many elements of the framework described in this report. We have yet to see the impact of the proposed policy, but it is nevertheless worth noting that the UK proposals constitute the first more comprehensive approach globally to set CCS policy beyond the first demonstration facilities.

The relative importance of the five market failures identified above will change over time. In particular, in the earlier stages ${ }^{6}$ achieving learning and overcoming capital market failures may be the prime reasons for supporting CCS. As the technology matures, the rationale for policy intervention will evolve (Figure 5). The emissions externality will become more important, and the associated policy instruments can provide the primary commercial driver for CCS. The need to address possible problems of market power in emitting sectors and in downstream transport and storage markets is present at all times.

Figure 5 Evolving rationale for policy intervention

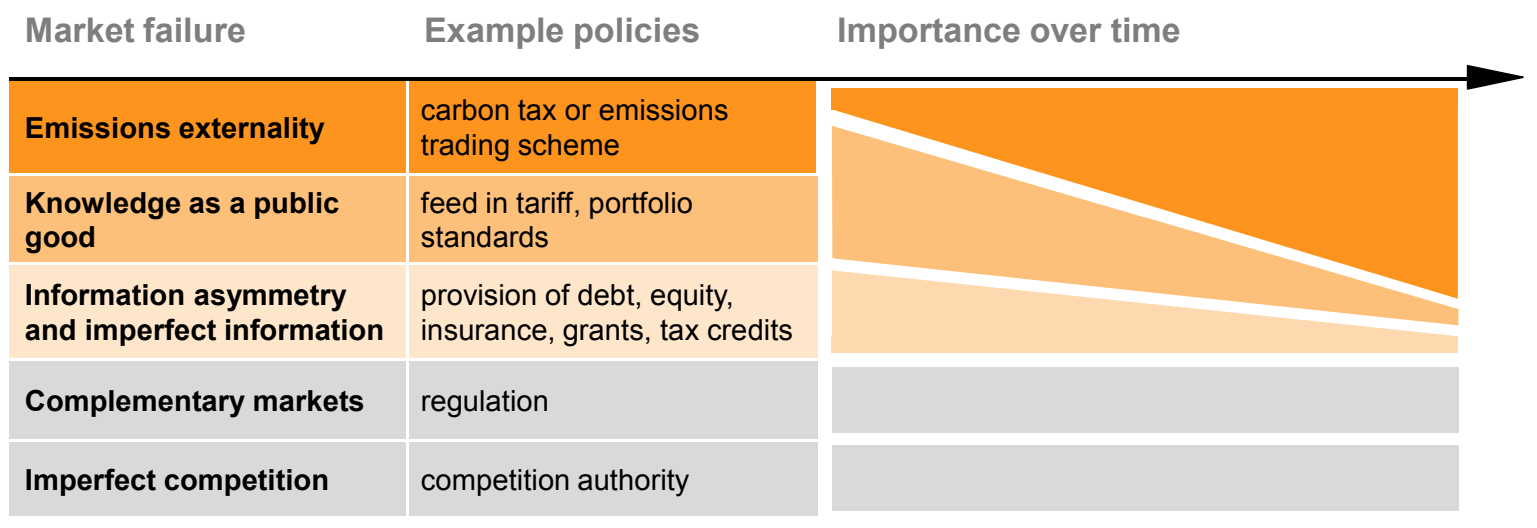

\footnotetext{
${ }^{6}$ After sufficient R\&D has been undertaken to demonstrate that the technology can work. As noted in IPCC (2005), this has been achieved by CCS.
} 


\section{Policy instruments}

For each market failure, a number of policy solutions exist. To support policy makers in the selection of instruments, this analysis examines the pros and cons of the most popular options. It examines four of the five market failures identified in the last section: externality, public good, information asymmetry and imperfect information, and complementary markets. Each section explores broad themes and policy instruments relevant to one issue and presents a table assessing policy options against appropriate criteria.

\section{Controlling carbon emissions}

\section{A variety of instruments}

There are six main types of instrument to tackle carbon emissions: an economy-wide cap-and-trade scheme, an economy-wide carbon tax, a $\mathrm{CO}_{2}$ purchasing contract, a baseline and credit scheme, a feebate scheme and an emissions performance standard.

The first four have the potential to be applied across a number of sectors or the whole economy:

- An economy-wide cap-and-trade scheme caps the total quantity of $\mathrm{CO}_{2}$ emissions from regulated sectors and creates an equivalent number of emissions allowances. Firms surrender an allowance for each tonne of $\mathrm{CO}_{2}$ emitted. They may buy these allowances from the government for a price or by auction, or may be given a proportion of them for free. This scheme places a cost on emissions, which firms can avoid by the use of CCS. The EU Emissions Trading Scheme (EU ETS) is the world's largest cap and trade scheme.

- An economy-wide carbon tax in which there is a tax on $\mathrm{CO}_{2}$ emissions or on fossil fuels. Firms may use CCS to reduce their tax liability. Norway currently has a carbon tax of between USD $18 / \mathrm{tCO}_{2}$ and USD 70/tCO 2 .

- $\mathrm{A} \mathrm{CO}_{2}$ purchasing contract is a legally binding agreement to purchase $\mathrm{CO}_{2}$ under certain terms and conditions from eligible sellers. It creates a liability which has to be funded either by taxpayers or electricity customers, with government or power suppliers acting as the contracting party on their behalf. It can be used to pay for CCS.

- A baseline and credit scheme establishes a baseline level of emissions for an installation, company or sector. This scheme rewards reductions below that baseline by providing credits that can be used for compliance purposes by those who have exceeded their baseline or face absolute emission limits in a linked cap-and-trade scheme. Under the Clean Development Mechanism (CDM), emissions reduction generates credits that can be sold to countries that have absolute emissions reduction targets under the Kyoto Protocol (as well as installations within the EU ETS). CCS projects are eligible to receive credits under the CDM.

The last two, by design, tend to have narrower, sector-specific applications:

- A feebate scheme is a carbon tax with an offset baseline. The tax applies to every unit of emissions above a set baseline, and tax credits are issued if emissions are below the baseline. It is possible to set the tax rate and baseline at levels at which there would be little difference in the cost to firms between paying the tax or investing in a particular abatement technology, such as CCS. 
- An emissions performance standard is a mandate applying either only to new investment or to all emitters in a sector, limiting firms or installations to no more than a set amount of emissions per unit of production. Either every installation complies with the standard, or the obligations are tradable, so that the standard is met on average across the sector. For example, there is currently a non-tradable emissions performance standard of $500 \mathrm{~g} \mathrm{CO}_{2} / \mathrm{kWh}$ on new electricity generating plants in California. If the limit is low enough, it may require use of CCS or other high cost technologies. A non-tradable emissions performance standard works best where all firms or installations make identical products, such as electricity. The United Kingdom is also establishing an emissions performance standard (see Box 2).

\section{Economy-wide carbon prices under a tax or cap-and-trade scheme may be preferable}

Economy-wide carbon prices, set either directly through a tax or indirectly through an emissions trading scheme, are the most efficient way to control carbon emissions. ${ }^{7}$ They send the same signal about the value of reducing emissions to each firm or person across all their activities. This allows emissions reduction at significantly lower cost than if command-and-control regulation or a narrower, sector-specific approach is adopted. (Both of these impose unequal costs across the economy.) A further benefit of carbon prices from an economic perspective is that they increase the prices of emissions-intensive products. This further promotes cost-effective emissions reduction, although it can raise concerns where lower-income households spend proportionately more of their income on emissions-intensive products (i.e. energy).

The choice between carbon taxes and emission trading schemes has been extensively debated. The debate turns on a number of factors, including political economy, uncertainty of $\operatorname{costs}^{8}$ and international scope; and one instrument may be preferred over another in specific cases (Hepburn, 2006). A more volatile carbon price, associated with cap-and-trade schemes, makes the returns on investment more uncertain, which may deter investment in high capital-cost options such as CCS (Laing and Grubb, 2010; Abadie and Chamarro, 2008). This effect can be mitigated by the introduction of price floors (and ceilings), although these require additional sophistication on behalf of policy-makers, and they bring the scheme closer in form to a feebate or tax. Trading schemes have been widely adopted, mainly for two political economy reasons: first, firms have benefited (at the cost of taxpayers) from free distributions of allowances, and second, governments have been attracted to direct policy control over the quantity of emissions.

Interventions to create a carbon price are a particularly good example of the possibility of policy failure. In order to make investments in long-lived low-carbon assets such as CCS, investors need assurance that the carbon pricing policy underpinning the investment will remain in place. However, investors might question the future credibility of the policy, especially if it conflicts with other government objectives (such as keeping energy prices low). Therefore, even in the

\footnotetext{
${ }^{7}$ In non-Annex 1 countries, the carbon price signal is likely to be provided in the short to medium term by some form of baseline and credit scheme, at either project or sectoral level. This is discussed more fully in the following section.

${ }^{8}$ According to the classic paper by Weitzman (1974), under uncertainty, a quantity instrument to control a pollutant such as $\mathrm{CO}_{2}$ is preferred when the additional damage caused by an extra unit of pollution is particularly high (i.e. when the slope of the marginal damage curve is relatively steep), and a price instrument is preferred when the cost of controlling an extra unit of pollution is particularly high (i.e. when the slope of the marginal abatement cost curve is thought to be steep). As $\mathrm{CO}_{2}$ is a "stock pollutant" (i.e. the extent of climate change will be determined by GHG concentrations in the atmosphere that have accumulated since the industrial revolution), this is often interpreted as implying that price instruments are preferred for combating global warming as the extra damage done by the release of one more tonne of $\mathrm{CO}_{2}$ is relatively low. However, in reality, these economic considerations have been less important in determining the choice between taxes and trading schemes than some political economy issues.
} 
presence of a carbon price that currently internalises the GHG externality, the risk of a future change in policy may deter investors from investment in capital-intensive assets such as CCS. One solution to this problem is to create an independent agency to determine the key implementation aspects of a carbon policy - analogous to the role that has been delegated to central banks in controlling inflation in many countries (Helm, Hepburn and Mash, 2003).

Building on these ideas, a more radical approach to establishing a long-term carbon price signal is to create a set of long-term permits granting (diminishing) GHG emission rights over the next century. This is complemented by a "central bank of carbon", analogous to a classic monetary central bank, that can issue additional emission permits in the short run, thus influencing the value of permits. The long-term permits are given out for free to households and firms, creating a political constituency with an interest in a high carbon price and a private financial motive to reduce their emissions. Long-term permits would be freely traded, creating a long-term price signal that gives a degree of certainty for investors, much like a long-term bond yield curve. Furthermore, the central bank of carbon can issue additional permits in the short run at a fixed price, effectively creating a price ceiling or safety valve, to ensure that compliance costs remain manageable. This hybrid system (McKibben and Wilcoxen, 2007) may be particularly suitable for encouraging and financing capital-intensive CCS investment: the market for long-term permits gives investors an idea of future carbon prices and allows them to hedge against volatility. Under this system, installing CCS technology would bring a greater immediate pay-off, as it would allow a firm to sell not just a single year's worth of emission rights in the present, but its entire holding of long-term emission rights corresponding to the emissions reduction. This front-loaded payout structure may facilitate the procurement of project finance, thus allowing more CCS projects to go ahead.

\section{Other policy instruments for specific sectors}

There are circumstances in which, rather than an economy-wide carbon price, sector-specific instruments such as a $\mathrm{CO}_{2}$ purchasing contract can be used to correct the carbon externality and may stimulate CCS. This can be desirable where:

- it is politically difficult to introduce an economy-wide carbon price;

- there is a need to de-carbonise a particular sector quickly; or

- the economy-wide carbon price needed to meet a particular emissions target results in adverse economic effects (for example, damaging the competitive position of firms competing with international rivals that do not face similar controls).

\section{Assessing policy options for controlling carbon emissions}

These policy options can be judged against four criteria: environmental effectiveness, costeffectiveness, ease of application, and political acceptability (Table 1):

- Environmental effectiveness: This is a function of how widely the instrument can be applied across different sectors and assets, the strength of the incentive it provides to invest in abatement, and whether or not it is likely to increase the price of products and hence reduce demand for emissions-intensive products.

- Cost-effectiveness: This is a function of whether or not the instrument encourages the least-cost abatement options and whether it helps to reduce costs of the individual options. For example, the cost-effectiveness of CCS can be enhanced by policy, which facilitates co-ordination between investment in capture, downstream transportation and 
storage.

- Ease of application: Policies may require different levels of institutional capability, often linked to the level of discretion used in operating them. The relative lack of information held by policymakers (compared to companies) may be more or less relevant, depending on the policy.

- Political acceptability: Policies may be more or less politically acceptable, depending on familiarity and confidence in the outcome, trust in institutions, impact on special interest groups, or the distribution of costs between firms, consumers and taxpayers. 
Table 1 An assessment of instruments to control carbon emissions

\begin{tabular}{|c|c|c|c|c|}
\hline Policy tool & $\begin{array}{l}\text { Environmental } \\
\text { effectiveness }\end{array}$ & Cost-effectiveness & Ease of application & $\begin{array}{l}\text { Political } \\
\text { acceptability }\end{array}$ \\
\hline $\begin{array}{l}\text { Cap- } \\
\text { and-trade } \\
\text { scheme }\end{array}$ & $\begin{array}{l}\text { Can be applied across } \\
\text { wide range of sectors } \\
\text { with knowledge that cap } \\
\text { will be met. Allowance } \\
\text { price volatility may } \\
\text { reduce policy efficiency. }\end{array}$ & $\begin{array}{l}\text { Abatement only } \\
\text { takes place if the } \\
\text { market reveals that it } \\
\text { is needed to meet } \\
\text { the cap, but cost will } \\
\text { not be known in } \\
\text { advance. }\end{array}$ & $\begin{array}{l}\text { The choice of market rules } \\
\text { may stimulate lobbying, } \\
\text { especially with more } \\
\text { complex designs. }\end{array}$ & $\begin{array}{l}\text { Provision of free } \\
\text { allowances can offset } \\
\text { the total cost increase. } \\
\text { Supports other low- } \\
\text { carbon options such } \\
\text { as fuel switching and } \\
\text { renewables. }\end{array}$ \\
\hline Carbon tax & $\begin{array}{l}\text { Can be applied across } \\
\text { a wide range of sectors, } \\
\text { but emission reductions } \\
\text { will not be known in } \\
\text { advance. }\end{array}$ & $\begin{array}{l}\text { Abatement only } \\
\text { proceeds if it is cost- } \\
\text { effective at tax rate, } \\
\text { so cost is controlled. }\end{array}$ & $\begin{array}{l}\text { An existing tax collection } \\
\text { infrastructure may make } \\
\text { introduction easier, but } \\
\text { firms may lobby for } \\
\text { exemptions or reliefs. }\end{array}$ & $\begin{array}{l}\text { Introduction of a new } \\
\text { tax may be politically } \\
\text { challenging, but } \\
\text { expected revenues } \\
\text { can be used to } \\
\text { facilitate this. }\end{array}$ \\
\hline $\begin{array}{l}\text { Hybrid: } \\
\text { long-term } \\
\text { emission } \\
\text { certificates } \\
\text { coupled } \\
\text { with central } \\
\text { bank of } \\
\text { carbon }\end{array}$ & $\begin{array}{l}\text { Can be applied across } \\
\text { a wide range of sectors, } \\
\text { with knowledge that the } \\
\text { cap is likely to be met. } \\
\text { Overshooting of } \\
\text { emissions is possible } \\
\text { due to central bank of } \\
\text { carbon printing } \\
\text { additional permits. }\end{array}$ & $\begin{array}{l}\text { Abatement only } \\
\text { proceeds if the } \\
\text { market reveals that it } \\
\text { is needed to meet } \\
\text { the long-term cap. } \\
\text { Costs can be } \\
\text { controlled by the } \\
\text { central bank of } \\
\text { carbon, which can } \\
\text { print additional } \\
\text { permits in the short } \\
\text { run to cap prices. }\end{array}$ & $\begin{array}{l}\text { Challenging, as new } \\
\text { institution would be } \\
\text { required, but similarity with } \\
\text { monetary central bank } \\
\text { may facilitate set-up } \\
\text { procedures. Temptation } \\
\text { for central bank of carbon } \\
\text { to constantly print short- } \\
\text { term permits is offset by } \\
\text { political pressure of long- } \\
\text { term permit owners. }\end{array}$ & $\begin{array}{l}\text { Free distribution of } \\
\text { long-term permits may } \\
\text { greatly ease } \\
\text { introduction and } \\
\text { create a constituency } \\
\text { interested in a high } \\
\text { and rising carbon } \\
\text { price. Resistance from } \\
\text { treasury/finance } \\
\text { ministry is possible, as } \\
\text { an opportunity for } \\
\text { government revenue } \\
\text { is foregone. }\end{array}$ \\
\hline $\begin{array}{l}\text { Baseline } \\
\text { and credit }\end{array}$ & $\begin{array}{l}\text { The lack of overall cap } \\
\text { limits environmental } \\
\text { effectiveness. }\end{array}$ & $\begin{array}{l}\text { Abatement only } \\
\text { proceeds if costs are } \\
\text { below credit price, } \\
\text { but lack of penalty } \\
\text { for emissions may } \\
\text { lead to some cost- } \\
\text { effective reductions } \\
\text { not being pursued. }\end{array}$ & $\begin{array}{l}\text { Requires expertise in } \\
\text { monitoring and evaluation. }\end{array}$ & $\begin{array}{l}\text { Absence of cash cost } \\
\text { on emissions below } \\
\text { the baseline makes it } \\
\text { attractive to regulated } \\
\text { parties. }\end{array}$ \\
\hline Feebate & $\begin{array}{l}\text { Allows some flexibility } \\
\text { around a target } \\
\text { emissions level. Difficult } \\
\text { to cover multiple } \\
\text { sectors with one } \\
\text { feebate. }\end{array}$ & $\begin{array}{l}\text { Abatement made } \\
\text { only if costs are less } \\
\text { than the fee rate; } \\
\text { costs are kept within } \\
\text { limits. }\end{array}$ & $\begin{array}{l}\text { Scope for lobbying for } \\
\text { level of baseline. } \\
\text { Technical aspects of } \\
\text { setting and updating } \\
\text { baseline (sufficient to } \\
\text { stimulate investment, but } \\
\text { no higher than that) also } \\
\text { very challenging. }\end{array}$ & $\begin{array}{l}\text { Attractive mixture of } \\
\text { environmental } \\
\text { certainty and cost } \\
\text { control, but difficult to } \\
\text { administer. }\end{array}$ \\
\hline $\begin{array}{l}\text { Emission } \\
\text { performance } \\
\text { standard }\end{array}$ & $\begin{array}{l}\text { Effective in controlling } \\
\text { emissions. Ambiguous } \\
\text { impact on demand for } \\
\text { goods. Has less effect if } \\
\text { only applied to new } \\
\text { plant, as life of old plant } \\
\text { may be prolonged. }\end{array}$ & $\begin{array}{l}\text { Can impose high } \\
\text { costs by setting the } \\
\text { same standard for } \\
\text { all players, } \\
\text { preventing } \\
\text { efficiencies from } \\
\text { trade. }\end{array}$ & $\begin{array}{l}\text { Difficult to impose on } \\
\text { heterogeneous sectors. } \\
\text { Standards are vulnerable } \\
\text { to lobbying, but } \\
\text { comparatively easy to } \\
\text { enforce, if general GHG } \\
\text { accounting standards are } \\
\text { high. More challenging } \\
\text { otherwise. }\end{array}$ & $\begin{array}{l}\text { Attracts little political } \\
\text { attention, but may be } \\
\text { fiercely lobbied } \\
\text { against. Likely to be } \\
\text { popular with } \\
\text { supporters of } \\
\text { renewables, as no } \\
\text { competition for state } \\
\text { resources. }\end{array}$ \\
\hline $\begin{array}{l}\mathrm{CO}_{2} \\
\text { purchase } \\
\text { contract }\end{array}$ & $\begin{array}{l}\text { Easily measured } \\
\text { emissions savings. }\end{array}$ & $\begin{array}{l}\text { Can be cost- } \\
\text { effective, especially } \\
\text { if contracts have } \\
\text { long tenor and are } \\
\text { competitively bid }\end{array}$ & $\begin{array}{l}\text { Care is needed when } \\
\text { drawing up contract, } \\
\text { particularly with regard to } \\
\text { liability arrangements. } \\
\text { Once in place simple to } \\
\text { administer. }\end{array}$ & $\begin{array}{l}\text { May be unpopular with } \\
\text { those not offered } \\
\text { contracts. There may } \\
\text { be objections to } \\
\text { "paying the polluter". }\end{array}$ \\
\hline
\end{tabular}




\section{Promoting learning}

\section{Learning generates public benefits and merits support}

Whether they are classed as part of the demonstration phase of a technology or during preliminary stages of mass deployment, early CCS projects produce learning effects, which benefit others who are not directly involved. Knowledge of what works and does not work at increasing levels of scale becomes public knowledge, as do opportunities for cost reduction. Everyone benefits, not only the company that makes the investment. This is additional knowledge, beyond that generated through R\&D programmes, which focus more on the technology components of CCS. As the IPCC notes (IPCC, 2005), individual components of the CCS technology chain are mature; and what is now required is their integration. Hence the emphasis in this report on learning obtained during demonstration and deployment.

In contrast to policy instruments that are more or less technology-neutral, the policy instruments discussed in this section aim to secure knowledge specific to CCS. Success is measured in terms of cost reduction or deployment of CCS, rather than in terms of abatement achieved. This is the argument, sometimes explicit, for support of renewables in the presence of carbon prices (Philibert, 2011).

\section{Learning supported early on by grants, later by quantity instruments}

The high unit costs and risks of demonstration projects at this stage necessitate publicly funded grants. These are being used to deliver early demonstration projects to a total investment cost of between USD 26.6 billion and USD 36.1 billion (IEA/CSLF, 2010). These have been used as part of the policy mix in the United States to support CCS demonstration projects (Box 3). After these initial demonstration projects, there is still much knowledge to be obtained, but the larger number of CCS plants involved in further learning puts the scale of investment beyond the reach of many governments. There are increasing benefits from mechanisms that place more of the performance risk on the private sector.

Faced with a similar challenge in the renewables sector, policymakers have generally tended to adopt policies that encourage deployment by fixing prices or quantities to make market revenues larger and more certain, while also placing delivery risk on firms (Vivid Economics, 2010). There has been considerable debate about whether mechanisms that fix prices or those that limit quantities have provided the better incentive to develop renewables. A number of studies have concluded that feed-in tariffs have been more cost-effective at securing capacity (IEA, 2008; Butler and Neuhoff, 2008; Lipp, 2007). However, in other cases, feed-in tariffs have been controversial, providing excessive returns to investors. Given that CCS does not generate any revenues outside the carbon market (with the possible exception of plants supplying $\mathrm{CO}_{2}$ for $\mathrm{CO}_{2}$ EOR), care must be taken when applying lessons from the debate on incentives for renewables to the CCS context, but a comparison is nonetheless instructive, especially as it highlights important differences in the cost structure of many renewable technologies compared to CCS. 
In the United States, two types of policy currently support CCS and help secure early-stage learning: federal financial support (including grants, federal loan guarantees and operating subsidies) and a state-level quantity instrument.

The US Department of Energy (DoE) provides co-funding for a large variety of CCS projects, covering both industry and the power sector. Direct funding programmes include the Clean Coal Power Initiative, providing approximately USD 800 million in co-funding to one retrofitted and two newly constructed CCS coal power plants (DoE, 2011a). According to the DoE, this leverages more than USD 2.2 billion in private finance and may lead to the capture of more than 4.5 million tonnes of $\mathrm{CO}_{2}$ per year (DoE, 2011a). In addition, USD 1 billion in federal funding has been awarded to the FutureGen 2.0 project, aiming to demonstrate both CCS and oxy-combustion technology. Once operating, this project is predicted to capture approximately 1.3 million tonnes of $\mathrm{CO}_{2}$ per year (DoE, 2011b). The DoE also provides funding for CCS from industrial sources with a USD 1.3 billion fund, dedicated to large-scale industrial CCS projects, and a USD 100 million fund, dedicated to innovative concepts for beneficial $\mathrm{CO}_{2}$ use projects (DoE, 2009). So far, funding from these two has been allocated to more than 25 projects, with the three largest projects "expected to capture and store a total of 6.5 million tons of $\mathrm{CO}_{2}$ per year [...] by the end of the demonstration period in September 2015" (DoE, 2011c).

Furthermore the federal government has offered up to USD 8 billion in federal loan guarantees for projects "that employ advanced technologies that avoid, reduce or sequester emissions of [...] greenhouse gases in the area of coal-based power generation, industrial gasification, and advanced coal gasification facilities" (DoE, 2008). So far one guarantee has been extended, covering USD 2.6 billion of loans to Tenaska Corporation for its USD 3.5 billion Taylorville Energy Center, which may capture and store up to 3 million tonnes of $\mathrm{CO}_{2}$ per annum when fully operating (Tenaska, 2009).

The federal government also offers a USD $20 / \mathrm{tCO}_{2}$ tax credit for up to 75 million tonnes of geologically stored $\mathrm{CO}_{2}$, reduced to USD $10 / \mathrm{tCO}_{2}$ used in EOR), with a possible aggregate value of up to USD 1.5 billion (GCCSI, 2009).

The state of Illinois has led the way in introducing a quantity instrument: starting in 2015, the state's electric power utilities are required to source $5 \%$ of their electricity from a clean coal power source. While the law expresses a target of $25 \%$ by 2025 , there is no provision in the current law for a regular annual increase in the legally required percentage. Plants operating before 2016 qualify as clean coal as long as at least $50 \%$ of $\mathrm{CO}_{2}$ emissions are capture and sequestered. This requirement rises to $70 \%$ for plants expected to commence operating in 2016 or 2017, and to $90 \%$ thereafter. (Illinois General Assembly, 2009).

A characteristic of many renewable electricity technologies is that the marginal costs of electricity production are low and stable. ${ }^{9}$ Consequently, a fixed price, such as through a feed-in tariff (FIT), provides reasonable certainty over the profit margin on each unit. However, in the case of CCS in the power sector, the energy costs of operating the CCS unit are considerable and vary as the price of fuel changes. When electricity prices change in response to fuel price changes, this provides a natural hedge. This would be lost under a fixed-price FIT. For this reason, it may be preferable to pay the FIT as a fixed top-up to market revenue (a premium). This approach has been used to promote the development of combined heat and power in Germany and, until

\footnotetext{
${ }^{9}$ This does not mean that the total cost of renewable technologies (as measured by the levelised cost of electricity) is low. In many cases, such technologies remain more expensive than conventional thermal generation (without CCS added). However, in the context of a fixed price, it is the size and volatility of the marginal costs that will determine the profit variability over the lifetime of the asset.
} 
recently, biomass electricity in China, with conventional fixed price FITs used for other renewable energy sources.

A quantity instrument in the form of a portfolio standard requires that an amount or proportion of output in a market be supplied by CCS-equipped plants. A number of studies have found these instruments to be somewhat ineffective at supporting renewables deployment (see Carley (2009)

Page | 24 for a discussion in the US context). However, this may reflect the cost characteristics of many renewable technologies which, as explained above, are well suited to fixed-price incentive mechanisms. By contrast, in the case of CCS, where costs are unknown and or volatile, quantitybased instruments may provide greater profit certainty to CCS investors in comparison to a conventional FIT. ${ }^{10}$ As with renewable portfolio standards, cost-effectiveness can be improved by making the obligation tradable, so that those on whom the obligation is placed may either comply directly or purchase certificates from others who are in surplus. If the trading takes place through an exchange, it has the advantage of revealing further information about the costs of CCS investment.

An important potential benefit of a quantity instrument is that it indicates the future level of demand to developers of transport, networks and storage, so (as discussed in Section 2.4) it might support the development of CCS infrastructure. Investors in these downstream services face less volume uncertainty as a result, and more capacity may be built.

\section{Other approaches may be needed outside the power sector}

The range of policy instruments to consider in the power sector is wider, because electricity trade across borders is limited in many countries. In other sectors, the range of options available is likely to be more restricted (ERM, 2009). For example, without substantial international coordination, it would be difficult to develop arrangements to provide a fixed price (or premium to that price) on steel or cement products that were produced in plants where CCS was fitted.

Some of the more attractive options that are particularly (although not exclusively) relevant outside the power sector include:

- Production or investment tax credits which reduce the tax liability faced by companies operating or installing CCS.

- Payments by governments for each tonne of $\mathrm{CO}_{2}$ captured and stored by a CCS plant. The size of these bonuses could be determined either administratively or by competitive bids. Like the quantity instruments referred to above, a bidding approach might have the advantage of providing more demand certainty to downstream transport and storage providers.

In regions with emission trading schemes, but where allowances are allocated for free, the funding for these incentive schemes may be met in part by transferring some of the implicit subsidy associated with the free allocation of allowances.

\footnotetext{
${ }^{10}$ In particular, tradable certificate regimes have often been criticised for creating a volatile revenue stream which reduces its value for investors contemplating a renewables investment (Stechow et al., 2011). However, in the case of a CCS tradable portfolio standard, this volatility may not be as damaging to investor confidence as the certificates would increase in price when the costs of operating a CCS plant became more expensive (i.e. when fossil-fuel prices increased). This correlation between costs and the value of certificate could dampen profit volatility, improving investment. It is noteworthy that the IEA (2008) reports that while FITs have generally delivered more cost-effective renewables deployment than quantity fixing measures, the results are more ambiguous for biomass technologies which, like fossil plants with CCS fitted, have significant marginal cost volatility and may be unsuited to fixed price FITs.
} 


\section{Assessing policy options to promote learning}

The following policy instruments could be used to encourage learning benefits:

- capital grant: public funding towards CCS construction (allocated either competitively or administratively);

- investment tax credits: a reduction in tax liabilities for firms that make a CCS investment;

- production subsidy: a payment for every tonne of $\mathrm{CO}_{2}$ stored as a result of a CCS investment (payment determined administratively or competitively);

- production tax credit: a reduction in tax liability for firms operating a CCS asset;

- FIT: a fixed price for all output where CCS is fitted;

- premium FIT: a premium added to price of all products produced where CCS is fitted; and

- CCS portfolio obligation: requirement that a certain percentage or amount of output be produced from CCS-fitted plants (can either be tradable or non-tradable).

The criteria used to assess these instruments (Table 2) are the same as those described earlier, with one exception: to reflect the technology-specific support of these policies, the first column examines the strength of the investment incentive created for CCS. 
Table 2 Policy tools used to tackle knowledge market failures and promote learning

Page | 26

\begin{tabular}{|c|c|c|c|c|}
\hline Policy & $\begin{array}{l}\text { Investment incentive } \\
\text { for CCS }\end{array}$ & Cost-effectiveness & Ease of application & Political acceptability \\
\hline Capital grant & $\begin{array}{l}\text { Environmental } \\
\text { effectiveness varies } \\
\text { with size and } \\
\text { conditions of grant; can } \\
\text { be applied to all } \\
\text { sectors and assets. }\end{array}$ & $\begin{array}{l}\text { May weaken incentive } \\
\text { to minimise lifecycle } \\
\text { costs; government } \\
\text { may fail to pick most } \\
\text { cost-effective projects. }\end{array}$ & $\begin{array}{l}\text { Expertise required to } \\
\text { select recipients and } \\
\text { set appropriate grant } \\
\text { level; prone to lobbying. }\end{array}$ & $\begin{array}{l}\text { Consumes scarce } \\
\text { fiscal resources; may } \\
\text { face opposition from } \\
\text { supporters of other } \\
\text { low-carbon } \\
\text { technologies. }\end{array}$ \\
\hline $\begin{array}{l}\text { Investment } \\
\text { tax credit }\end{array}$ & $\begin{array}{l}\text { Incentive depends on } \\
\text { size of credit; can be } \\
\text { applied to all sectors, } \\
\text { but only relevant for } \\
\text { firms with tax liabilities. }\end{array}$ & $\begin{array}{l}\text { Market selects which } \\
\text { projects to implement. } \\
\text { Does not guarantee } \\
\text { operation of the plant. }\end{array}$ & $\begin{array}{l}\text { Straightforward } \\
\text { administration; some } \\
\text { technical expertise } \\
\text { required to set } \\
\text { appropriate level. }\end{array}$ & $\begin{array}{l}\text { Consumes scarce } \\
\text { fiscal resources; may } \\
\text { face opposition from } \\
\text { supporters of other } \\
\text { low-carbon } \\
\text { technologies. }\end{array}$ \\
\hline $\begin{array}{l}\text { Production } \\
\text { subsidy }\end{array}$ & $\begin{array}{l}\text { Can cover every sector } \\
\text { and encourages } \\
\text { operation. }\end{array}$ & $\begin{array}{l}\text { High utilisation is } \\
\text { encouraged, and } \\
\text { market selects which } \\
\text { projects to fund. }\end{array}$ & $\begin{array}{l}\text { Expertise required to } \\
\text { select recipients and } \\
\text { set appropriate subsidy } \\
\text { level; prone to lobbying. }\end{array}$ & $\begin{array}{l}\text { Consumes scarce } \\
\text { fiscal resources; may } \\
\text { face opposition from } \\
\text { supporters of other } \\
\text { low-carbon } \\
\text { technologies. }\end{array}$ \\
\hline $\begin{array}{l}\text { Production } \\
\text { tax credit }\end{array}$ & $\begin{array}{l}\text { Effectiveness depends } \\
\text { on size of credit; can } \\
\text { be applied to all } \\
\text { sectors but only } \\
\text { relevant for firms with } \\
\text { tax liabilities; } \\
\text { encourages operation. }\end{array}$ & $\begin{array}{l}\text { High utilisation is } \\
\text { encouraged, and } \\
\text { market selects which } \\
\text { projects to fund. }\end{array}$ & $\begin{array}{l}\text { Expertise required to } \\
\text { select recipients and } \\
\text { set appropriate subsidy } \\
\text { level; prone to lobbying. }\end{array}$ & $\begin{array}{l}\text { Consumes scarce } \\
\text { fiscal resources; may } \\
\text { face opposition from } \\
\text { supporters of other } \\
\text { low-carbon } \\
\text { technologies. }\end{array}$ \\
\hline FIT & $\begin{array}{l}\text { Difficult to implement } \\
\text { outside electricity } \\
\text { sector; in electricity } \\
\text { sector, exposure to } \\
\text { fluctuating fuel prices } \\
\text { may lessen } \\
\text { investment. }\end{array}$ & $\begin{array}{l}\text { Market selects which } \\
\text { projects to implement; } \\
\text { but increased } \\
\text { exposure to fuel price } \\
\text { volatility may raise } \\
\text { risks. }\end{array}$ & $\begin{array}{l}\text { Templates transferable } \\
\text { from the renewables } \\
\text { sector, though volatility } \\
\text { of fuel costs for CCS } \\
\text { may require different } \\
\text { contractual } \\
\text { arrangements, }\end{array}$ & $\begin{array}{l}\text { Country-specific } \\
\text { factors will determine } \\
\text { whether resulting } \\
\text { higher prices have } \\
\text { lower or higher profile } \\
\text { than fiscal measures. } \\
\text { Likely to face } \\
\text { opposition from } \\
\text { supporters of other } \\
\text { low-carbon } \\
\text { technologies. }\end{array}$ \\
\hline Premium FIT & $\begin{array}{l}\text { Difficult to implement } \\
\text { outside electricity } \\
\text { sector; in electricity } \\
\text { sector can be effective } \\
\text { in delivering output. }\end{array}$ & $\begin{array}{l}\text { Market selects which } \\
\text { projects to implement, } \\
\text { and hedging of fuel } \\
\text { costs is preserved. }\end{array}$ & $\begin{array}{l}\text { Templates transferable } \\
\text { from the renewables } \\
\text { sector. }\end{array}$ & $\begin{array}{l}\text { Country-specific } \\
\text { factors will determine } \\
\text { whether resulting } \\
\text { higher prices have } \\
\text { lower or higher profile } \\
\text { than fiscal measures. } \\
\text { Likely to face } \\
\text { opposition from } \\
\text { supporters of other } \\
\text { low-carbon } \\
\text { technologies. }\end{array}$ \\
\hline $\begin{array}{l}\text { Portfolio } \\
\text { standard }\end{array}$ & $\begin{array}{l}\text { Unsuitable for sectors } \\
\text { with few plants per } \\
\text { firm; offers quantity } \\
\text { certainty. }\end{array}$ & $\begin{array}{l}\text { Unit costs are not } \\
\text { limited, but market } \\
\text { forces may deliver } \\
\text { least cost outcome. }\end{array}$ & $\begin{array}{l}\text { Similar expertise } \\
\text { required to other } \\
\text { instruments and } \\
\text { templates transferable } \\
\text { from renewables } \\
\text { sector. }\end{array}$ & $\begin{array}{l}\text { Country-specific } \\
\text { factors will determine } \\
\text { whether resulting } \\
\text { higher prices have } \\
\text { lower or higher profile } \\
\text { than fiscal measures. }\end{array}$ \\
\hline
\end{tabular}




\section{Capital and financial markets}

Investors' lack of information regarding the performance characteristics of CCS and the capital costs of setting up new commercial arrangements can discourage, limit or even prevent the flow of capital to CCS projects. This is only likely to be a difficulty while CCS is an early-stage technology. Government intervention can help, in effect purchasing knowledge and disseminating it to capital markets. Over time, as the risks become better known and possibly decline, the need for intervention may decline, with the private sector more willing to take them on and provide a greater allocation of capital for CCS projects.

\section{Several approaches to novelty, capital and financial market risk}

During the early stages of CCS adoption, capital financial markets may be slow to provide finance. Capital providers and financial intermediaries may have insufficient knowledge to distinguish good projects from bad ones, and this may make them reluctant to supply much or any capital.

The public sector, either governments or International Financial Institutions (IFIs), can assist in a number of ways, including direct contribution of capital or risk mitigation instruments:

- Direct contribution of capital: This expands the pool of available capital and helps the sector to achieve scale and experience. This approach has been used by some governments to support the development of nuclear power plants where finance requirements are substantial and there are analogous public policy issues regarding longterm liability and storage. It requires a high level of sophistication in drafting the terms of debt or equity participation to avoid dampening incentives to manage projects well. It only works where the principal project sponsors are motivated to seek co-investment. Provision of capital is an appropriate policy when the overall level of capital allocation which private investors are willing to make to CCS falls below the ambition of a particular policy programme. Public sector capital provision can help relieve such constraints and bring a sector through its novel phase to a more mature phase.

- Risk mitigation instruments such as credit guarantees and insurance: These tools explicitly alter the risk allocation, and aim to lever in risk-averse private sector capital. In doing so, they would have to avoid diluting the project managers' incentives and attracting poor quality projects. These instruments may be particularly appropriate for cross-border investment. These have also been used in the nuclear industry in some countries, including the United States. In contrast, as noted above, risk mitigation instruments alter the distribution of risk. Insurance may help when there are specific risks that deter private sector investment, and insurance can be useful where risks can be diversified across projects within the sector. Insurance can create problems, however, particularly if it encourages excessive risk-taking (moral hazard).

Both policies allow the public sector to be involved in supervising projects, which offers opportunities to acquire information. For instance, all CCS projects that are co-financed by the US Department of Energy include knowledge sharing as part of the terms and conditions of providing co-financing.

However, to protect their commercial interests, co-investors may seek to limit the public sector from sharing the acquired information more widely. If the government is able to facilitate the syndication of capital to projects once they have become established, it will likely be better able to distribute information when the project is refinanced. In some cases IFIs may be better placed to provide these instruments than national governments, as discussed in the next section. 
The risks will gradually become better known and controlled, and the private sector will be more willing and able to take them on. Hence public intervention can be transitory, perhaps limited to demonstration projects and the first fleet of commercial plants in a sector.

\section{Assessing policy options for capital and financial markets}

Page | 28 Given the focused nature of the instruments in this section, in this assessment of policy options (Table 3) the first column also examines the strength of the investment incentive created for CCS.

Table 3 Policies used to tackle capital and financial market failures

\begin{tabular}{|c|c|c|c|c|}
\hline Policy & $\begin{array}{l}\text { Investment incentive for } \\
\text { CCS }\end{array}$ & Cost-effectiveness & Ease of application & $\begin{array}{l}\text { Political } \\
\text { acceptability }\end{array}$ \\
\hline $\begin{array}{l}\text { Co- } \\
\text { investment } \\
\text { equity }\end{array}$ & $\begin{array}{l}\text { Increases scale more } \\
\text { quickly and accelerates } \\
\text { learning. Gives investor } \\
\text { confidence about long- } \\
\text { term policy because the } \\
\text { state is involved. }\end{array}$ & $\begin{array}{l}\text { Public participation } \\
\text { may enable greater } \\
\text { inter-sponsor } \\
\text { cooperation and } \\
\text { system integration. }\end{array}$ & $\begin{array}{l}\text { Requires financial and } \\
\text { commercial expertise } \\
\text { within government and } \\
\text { ability to carry out due } \\
\text { diligence on projects. } \\
\text { Only works if projects' } \\
\text { sponsors are } \\
\text { supportive. }\end{array}$ & $\begin{array}{l}\text { Depends on existing } \\
\text { precedents and } \\
\text { political outlook. }\end{array}$ \\
\hline $\begin{array}{l}\text { Provision } \\
\text { of debt }\end{array}$ & $\begin{array}{l}\text { May give assurance to } \\
\text { other debt providers and } \\
\text { help to prove commercial } \\
\text { models. }\end{array}$ & $\begin{array}{l}\text { Will not affect project } \\
\text { costs directly, but } \\
\text { may accelerate } \\
\text { learning. }\end{array}$ & As above. & $\begin{array}{l}\text { Depends on existing } \\
\text { precedents and } \\
\text { political outlook. }\end{array}$ \\
\hline $\begin{array}{l}\text { Credit } \\
\text { guarantees }\end{array}$ & $\begin{array}{l}\text { Effective where projects } \\
\text { are already close to } \\
\text { achieving a working } \\
\text { capital structure. }\end{array}$ & $\begin{array}{l}\text { Any weakening of } \\
\text { incentives on } \\
\text { managers or other } \\
\text { investors is to be } \\
\text { avoided; otherwise } \\
\text { costs may rise. }\end{array}$ & As above. & $\begin{array}{l}\text { It may be difficult for } \\
\text { government to take } \\
\text { on liabilities which } \\
\text { could be triggered } \\
\text { by poor managerial } \\
\text { decisions. }\end{array}$ \\
\hline $\begin{array}{l}\text { Insurance } \\
\text { products }\end{array}$ & $\begin{array}{l}\text { May help to achieve } \\
\text { broader capital } \\
\text { participation. }\end{array}$ & $\begin{array}{l}\text { May enhance } \\
\text { competition between } \\
\text { capital providers, but } \\
\text { may also reduce } \\
\text { incentives to control } \\
\text { specific risks. }\end{array}$ & As above. & $\begin{array}{l}\text { It may be difficult for } \\
\text { government to take } \\
\text { on liabilities which } \\
\text { could be triggered } \\
\text { by poor managerial } \\
\text { decisions. }\end{array}$ \\
\hline
\end{tabular}

\section{Transport and storage}

CCS deployment may be affected by a lack of certainty about the provision of transport and storage infrastructure; and the natural monopolies in transport (and potentially storage) could create a tendency to under-provide services. Policies may be used beneficially to steer the development of infrastructure, giving more certainty to capture plant operators, and promoting adequate provision of infrastructure.

\section{Remedies for lack of certainty in demand for infrastructure}

Seeing uncertainty in demand, private investors may hesitate to invest in CCS infrastructure. Demand for infrastructure services depends on government policy, the development of CCS technology, the development of substitute technologies and the commercial fortunes of energy users. A comprehensive infrastructure solution is therefore unlikely to emerge - or, indeed, be desirable - until some uncertainties have diminished. During early stages of 
deployment, to minimise the scale of assets at risk of stranding, transport infrastructure is likely to develop as point-to-point links between emitters and stores, or as small clusters linked to stores. This limits the quantity of capital exposed, and means that some could be delivered on a vertically integrated project basis.

Over time, vertically integrated bilateral links could be superseded by infrastructure clusters, in line with CCS deployment in a single sector. This would provide better coverage, reduced costs through economies of scale, and higher resilience. Government, acting directly or through an agent, could aggregate volume information from capture plant operators and provide planning of infrastructure system development.

If and when the widespread deployment of CCS becomes probable, infrastructure clusters may be combined into an integrated system solution with public supervision. Since volume may be more uncertain outside the power sector, it may have a role in underwriting a proportion of the fixed network costs

\section{Policy options to improve certainty for network, storage and capture operators}

To give security to network and/or storage operators, governments could boost demand, guarantee market share, guarantee returns on capital or underwrite risk on contracts. It could also undertake a number of these options simultaneously. For example, it could increase the certainty and level of demand by setting up instruments to buy the output of capture plant (such as a $\mathrm{CO}_{2}$ contract or producer obligation), thereby increasing the volume of $\mathrm{CO}_{2}$ produced for storage. Having done this, it could also require the upstream party to write a take-or-pay contract where that party must pay the value of the contract, whether or not they make use of the service. This is easier to implement when the party is state-owned or has some way to pass costs on to its customers.

A guarantee of demand at market level does not translate into a guarantee of demand for a network or store operator, because there is a risk that rivals will compete and take market share. This risk can be eliminated by creating a franchise. A franchise allows competition for the market when the franchise is being set up, but once it has been set up, there is no further competition within the market. Certainty is improved for the operator, but there is a loss of the benefits of enduring competition.

A further possibility is that government could guarantee recovery of costs for network or storage operators by establishing a claim on other parties, perhaps through a levy or the regulatory asset base of an established utility whose financing is guaranteed. This is a way to achieve a low cost of capital, but it comes at the expense of weaker incentives to set capacity in response to market demand. Finally, the government could write contract insurance to offset counterparty risk.

To give security to capture plant operators, government could introduce a right to connect to the network and establish terms of contract which provide for compensation in the event that the network or storage becomes unavailable. Government could also provide a long term for the contracts and include clauses that ensure reasonable prices and terms upon contract renegotiation. Counterparty risk could be reduced through a special administration regime for the network and storage operator, such that the service is sure to continue in the event that the operator goes out of business. 


\section{Public supervision of market power}

Due to economies of scale and land use restrictions, entry into the transport market may be extremely difficult for competitors once an incumbent is established. Transport infrastructure may therefore become a natural monopoly, requiring regulatory oversight of pricing and third party access rights.

Storage may require more or less public supervision than transport. The composition of the storage market will depend on the geological availability of storage sites, economies of scale and political choices. In a scenario where the number of independent stores connected to a network is small and owned by just a limited number of firms, public supervision would be required to prevent adverse monopoly behaviour. Alternatively, storage could be integrated with transport or publicly owned. In a scenario with multiple independently owned stores, competition may flourish, and intervention beyond establishing environmental and safety regimes and providing for liabilities might not be necessary.

There are inherent advantages and drawbacks to the different models for development and oversight of storage markets and infrastructure (Table 4).

Table 4 Models for infrastructure development and oversight

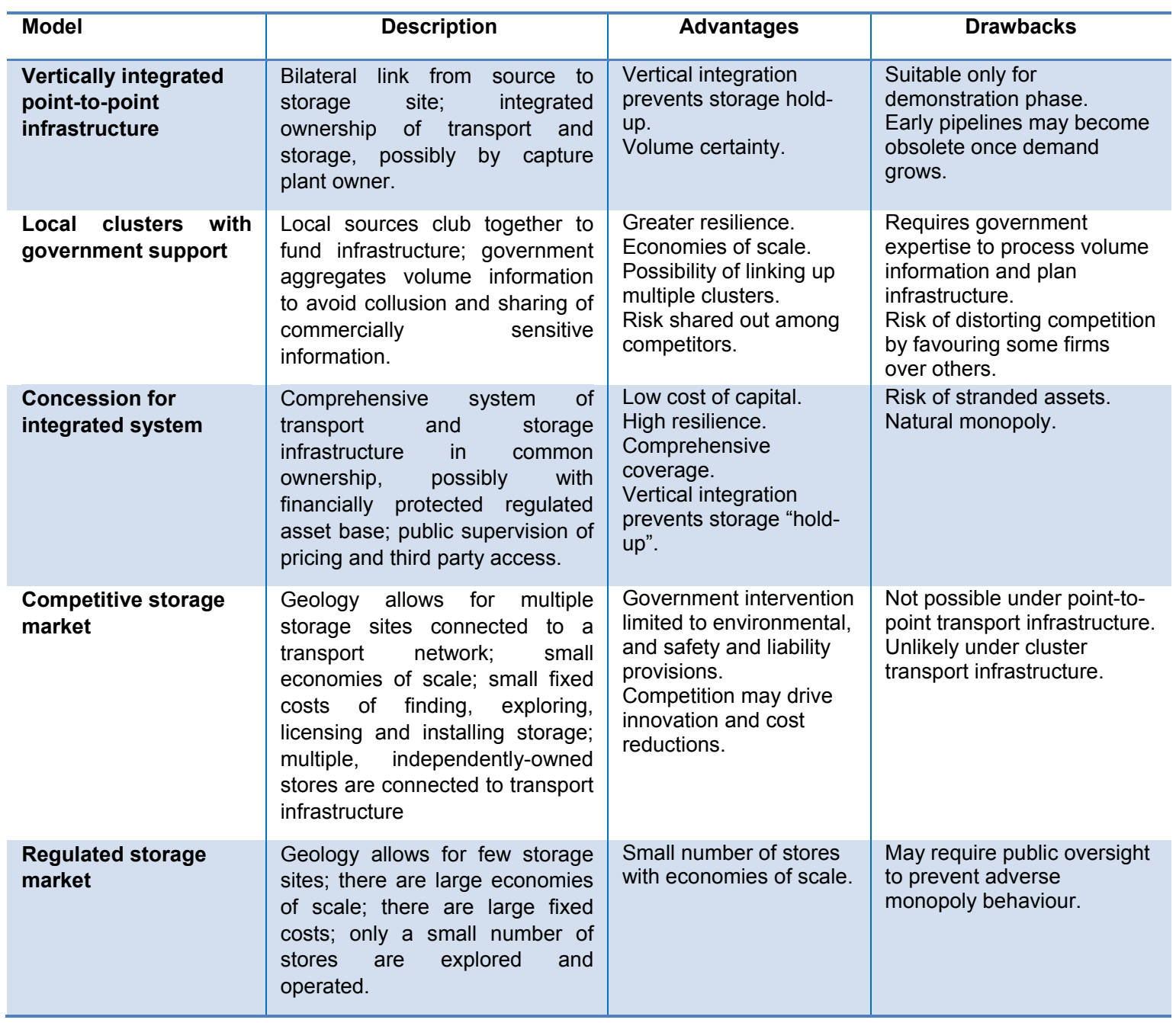




\section{Sector and country assessment}

Many challenges associated with CCS deployment are common across all sectors where CCS is feasible, including site selection, monitoring and project approvals. It is easiest to prioritise learning on these issues in appropriate pilot sectors - those with low trade exposure, low CCS costs, and high $\mathrm{CO}_{2}$ emissions. The processing of natural gas and the power sector (in some regions) fulfil these criteria, although there may be trade-offs between criteria. The portfolio of early projects must have sufficient sectoral diversity to meet needs for learning specific to other sectors. The degree of trade exposure, market structure and country-specific features will influence the choice and mix of policy instruments. Incentives for CCS in the developing world might use a baseline and credit scheme, with public support from developed countries and active involvement of IFIs.

\section{Selecting pilot sectors}

Many challenges associated with CCS deployment are common across all sectors where CCS is feasible, including site selection, monitoring and project approvals. It makes sense to prioritise learning on these issues and then prioritise mass deployment in appropriate sectors. Deployment across more difficult or costly sectors can follow.

There are a number of factors to consider when prioritising sectors. First, the same incentive may stimulate more projects in sectors where the cost of CCS is relatively low than in high-cost sectors, offering greater learning benefits. Second, a trade-exposed sector may require a more sophisticated set of incentives. This more complicated policy prescription makes trade-exposed sectors less suitable for pilot projects. Third, a sector with large $\mathrm{CO}_{2}$ emissions offers more opportunities to fit CCS, and more scope for learning, as more projects may be realised and a wider range of CCS technologies may be tested.

A comparison of the power, cement, steel, natural gas processing and refineries sectors in four European countries (Germany, the Netherlands, Norway and the United Kingdom) suggests that the natural gas processing and the power sector may be most suited for early CCS deployment in Europe (Figure 6). A similar analysis for the United States (Figure 7) shows that the natural gas processing sector may be best placed for pilot projects, as trade exposure for this sector is lower than in Europe, although it provides limited scope for later deployment due to comparatively low overall emissions.

Some of the expected learning will be sector-specific, such as learning to process flue gas with additional biological impurities (from combustion of biomass) or monitoring leakage in enhanced oil recovery (EOR) fields. To ensure that this learning is captured, the portfolio of early projects will need to include some projects in more challenging sectors.

Using captured $\mathrm{CO}_{2}$ for EOR may help reduce piloting costs, allowing larger investments and faster learning. EOR may, therefore, be among the earlier storage options to explore (Box 4). However, the extent to which EOR can usefully contribute to climate goals is unclear, since it allows additional extraction and combustion of fossil fuels. Further analysis of these issues is currently being undertaken by the IEA. 
Figure 6 Comparing power, cement, steel, natural gas processing and refineries sectors in Europe

Page | 32

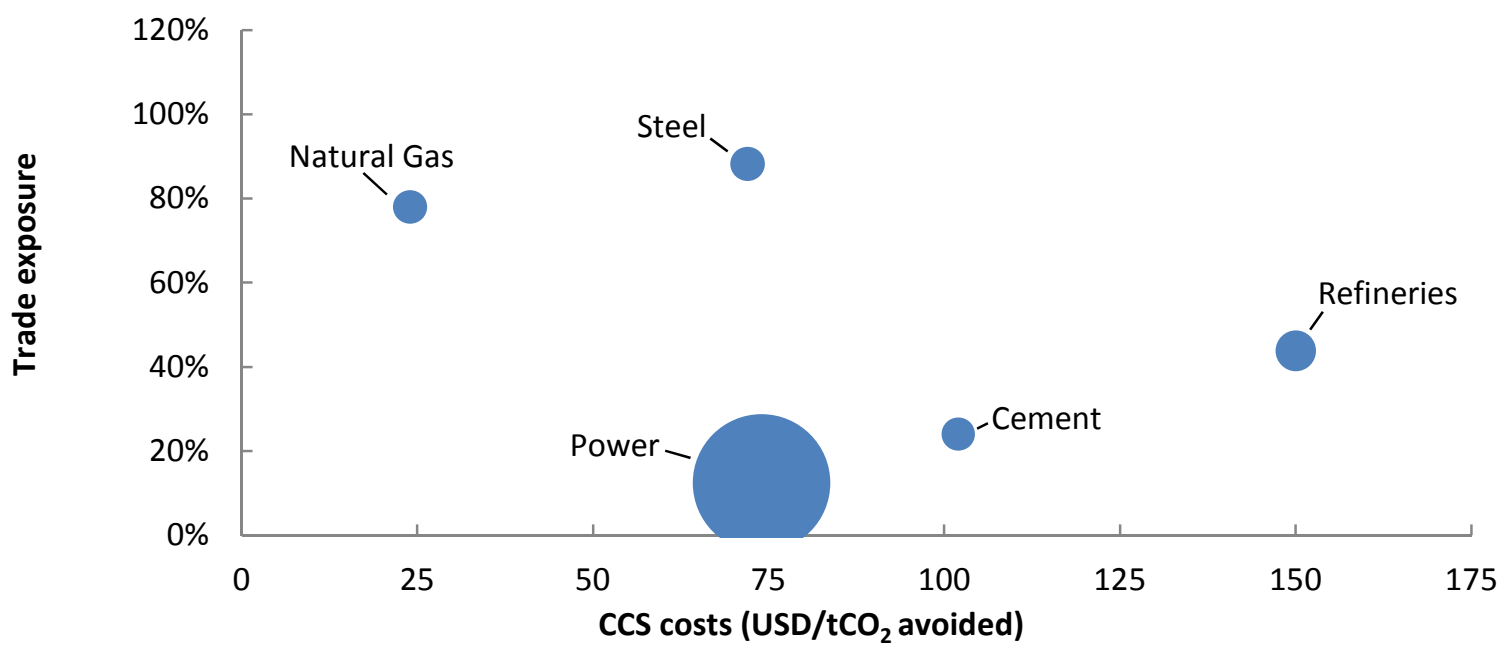

Notes: Data was collected for Germany, the Netherlands, Norway and the United Kingdom. Trade exposure measured as the sum of imports and exports divided by the sum of domestic production plus imports (measured in ktoe for the power and natural gas sectors; tonnes for steel, cement and refinery products). Bubble size corresponds to total emissions in 2010. Natural gas emissions also include emissions from crude oil production, and hence show an upper bound estimate.

Sources: IEA (2009) and Armstrong (2011) (cost: upper end estimate used to reflect early deployment); Eurostat (emissions); DESTATIS, WB WITS, BDZ, MWV, IEA, EEF, MPA, DUKES, CBS, VNPI, NP and SSB (trade exposure).

Figure 7 Comparing power, cement, steel, natural gas processing and refineries sectors in the United States

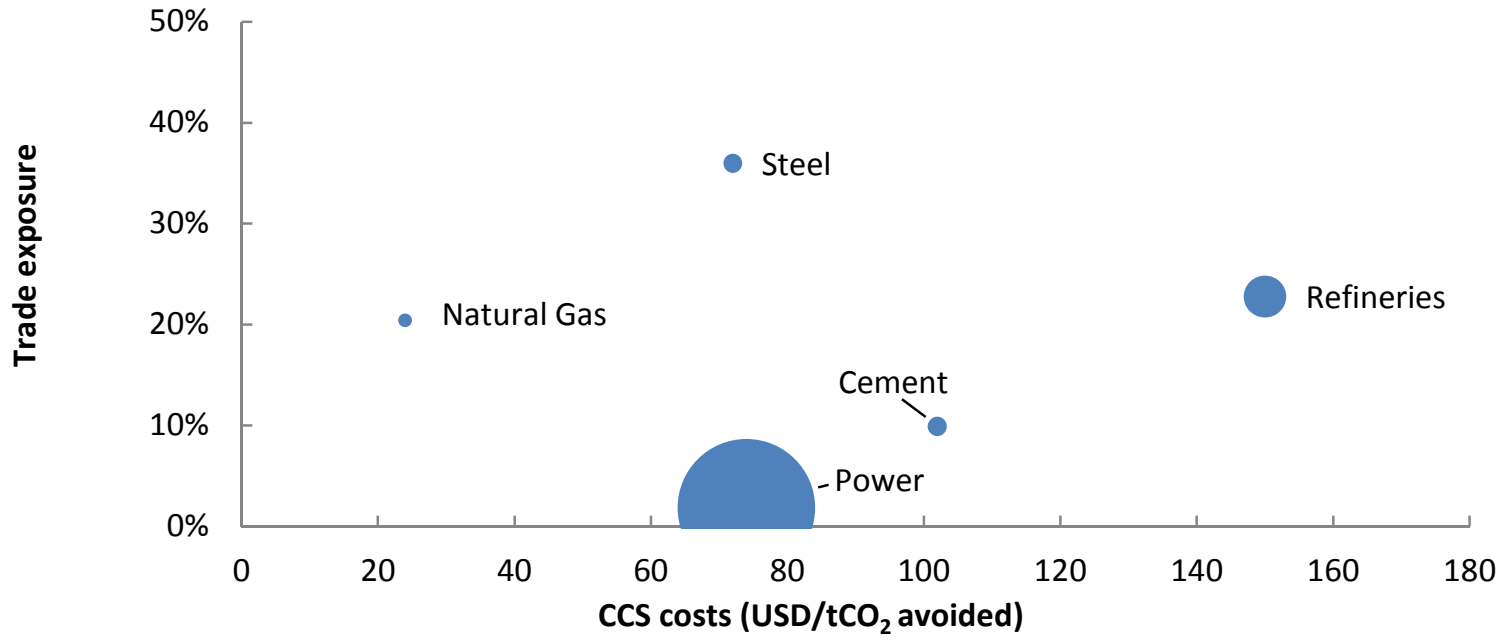

Notes: Trade exposure measured as the sum of imports and exports divided by the sum of domestic production plus imports. Power and natural gas measured in ktoe; steel, cement and refinery products in USD. Bubble size corresponds to total emissions (2008 for power and natural gas, 2009 for refineries, steel and cement).

Sources: IEA, 2009 and Armstrong (2011) (cost: upper end estimate used to reflect early deployment); EPA and EIA (emissions); IEA, (2010a and 2010b), US Census Bureau (trade exposure). 
One of the storage options available for $\mathrm{CO}_{2}$ is as a propellant for the extraction of oil from mature oil fields, using a process called enhanced oil recovery (EOR). Although approximately $20 \%$ to $40 \%$ of the $\mathrm{CO}_{2}$ used exits the field together with the recovered oil (MITEI, 2010), a large share of the $\mathrm{CO}_{2}$ does remain stored underground when the $\mathrm{CO}_{2}$ exiting the field is recovered and again injected.

It is important to distinguish between commercial EOR and climate-policy oriented EOR (CPO-EOR). Commercial EOR currently uses mainly $\mathrm{CO}_{2}$ co-produced with natural gas as well as naturally occurring $\mathrm{CO}_{2}$, and aims to produce a maximum of oil using a minimum of $\mathrm{CO}_{2}$. $\mathrm{CPO}-\mathrm{EOR}$ would use captured anthropogenic (CCS) $\mathrm{CO}_{2}$, and would aim at producing oil using and storing as much $\mathrm{CO}_{2}$ as possible. This tension is recognised in MITEI (2010): "the EOR operator wants to minimize the $\mathrm{CO}_{2}$ needed for producing a barrel of oil, while the power plant operator and EPA want to maximize CCS". In a similar vein, Leach et al. (2009) note that commercial EOR operators are relatively insensitive to climate policy: "(Cumulative sequestration) is much more responsive to oil-price increases than to increases in the carbon tax. Only at very high taxes does a trade-off between oil output and sequestration arise."

While commercial EOR is a mature process in the United States, with a regulatory framework and "a few thousand miles of commercial $\mathrm{CO}_{2}$ pipeline" in place (MITEI, 2010), CPO-EOR is not yet a mature technology. The long-term storage integrity of oil fields that have been exploited with multiple wells has yet to receive serious scientific investigation. For reasons explained above, new technologies that may improve the ratio of stored $\mathrm{CO}_{2}$ to oil production have not been used in commercial EOR and require testing. A report commissioned by DECC (2010) points out that "some approaches for $\mathrm{CO}_{2}$ EOR that attempt to better increase $\mathrm{CO}_{2}$ storage can store more $\mathrm{CO}_{2}$ than is associated with the $\mathrm{CO}_{2}$ emissions over the life cycle of the incremental oil produced from $\mathrm{CO}_{2}$-EOR, including emissions from consumption". However, these approaches remain experimental and require large-scale testing before they can be rolled out.

Furthermore, in order to fully understand the net $\mathrm{CO}_{2}$ savings from CPO-EOR, lifecycle analysis of EOR projects must to be undertaken, accounting for the "emissions from operating the CCS project, including the energy required to separate and re-inject the more than half to two-thirds of the injected $\mathrm{CO}_{2}$ produced along with the oil" (MITEI, 2010). In sum, firm policy recommendations will not be made until substantive further research on CPO-EOR is complete.

\section{Locally appropriate policy}

Both national characteristics and the features of specific sectors present challenges that influence the choice of policy instruments.

\section{Trade-exposed sectors}

CCS is currently a high-cost method of $\mathrm{CO}_{2}$ abatement, because its costs are higher than prevailing carbon prices. In trade-exposed sectors (such as steel and, in some locations, refining), unilateral introduction of policy instruments which impose costs on the private sector can, if not managed carefully, create a risk of displacing manufacturing activity to locations where CCS is not required. Where government covers the costs of CCS, the risk of displacing manufacturing 
activities is reduced or eliminated. ${ }^{11}$

\section{Market structure}

Concentrated sectors that are already subject to regulation call for a different range of policy options than sectors with a more diffuse and international supply base. Mechanisms that rely on competitive interaction between firms (such as a tradable portfolio standard) can only be used when there are a sufficient number of firms within the sector to allow development of a liquid market and enhanced competition. A trade-based policy confined to too small a group of firms or assets may reduce competition.

\section{Country-specific features ${ }^{12}$}

Public sector involvement generally diminishes over time, as learning declines and the scale of CCS activity increases. However, in some countries greater public sector involvement may be desirable, particularly if:

- government wishes to manage the CCS programme (for example to ensure a portfolio of different technologies, to force knowledge sharing or to achieve a particular geographic distribution of investment);

- government owns the sectors involved;

- CCS is seen as a strategic investment for the country;

- the investment helps to build the country's technical capability;

- the sectors involved are heavily trade-exposed and the country is working hard to grow its exports; or

- regulation or political concerns prevent pass-through of costs to customers (in the electricity sector).

In some countries, it may be preferable to place the burden on the private sector, particularly when the costs are large relative to available public funds and when it is difficult for government to commit future administrations to continue the funding.

Another important country-specific factor is sub-surface storage potential. Considerably more public intervention is likely to be required to regulating access to storage sites in countries where there are only a few sites than in countries where there are many sites.

The political philosophy and expertise of governments are also important factors (Finon, 2010). Governments in countries with a tradition of publicly owned companies (such as Norway) may wish to fund and manage CCS development directly. Governments that have traditionally favoured private provision (such as the United States) may prefer minimal direct government involvement.

\section{CCS incentives for developing countries}

The IEA CCS Roadmap (IEA, 2009) envisages that the total additional cost of deploying CCS outside OECD member countries will amount to almost USD 3 trillion by 2050. This is more than

\footnotetext{
${ }^{11}$ As noted earlier, in countries where trading schemes are already in place, the costs of government support may be wholly or partly compensated by reducing the implicit subsidy provided by free allowance allocation.

${ }^{12}$ The challenges associated with CCS incentives in developing countries are discussed below.
} 
half of the total cost of CCS envisaged in the Roadmap. While the bulk of the early deployment is expected in developed countries, the Roadmap aspires that, as early as 2020,50 out of 100 projects will be in non-OECD countries.

Much of the earlier analysis of incentive and financing mechanisms applies equally to all countries. The same shifts in policy emphasis - from technology-specific to technology-neutral policies; from capital support to operating support; and from public to private support - are likely to be warranted in all regions, as is the use of policy gateways to structure these shifts.

However, in the developing world, some important differences must be taken into account.

\section{Setting carbon prices through baseline- and credit-type mechanisms}

In the short-to-medium term, many developing countries are unlikely to introduce carbon pricing and prices are generally quite likely to remain modest. The carbon price signal is more likely to be provided through some form of baseline and credit scheme that provides financial incentives for reductions in emissions, but does not impose additional costs when emissions comply with the baseline.

Currently, this incentive is provided by the CDM, which allows developed countries to meet their caps by purchasing credits (Certified Emission Reductions) from projects that reduce emissions in the developing world. Although there is uncertainty about how the CDM will evolve when the Kyoto Protocol expires at the end of 2012, it seems likely that some form of project-based crediting scheme will persist. To date, CCS projects have not been permitted within the CDM. However, at the 2011 Climate Change Conference (COP/MOP) in Durban agreement on the modalities and procedures for including CCS in the CDM was reached. This allows CCS projects in developing countries to receive CDM credits.

Possible leakage of $\mathrm{CO}_{2}$ from capture sites is a particularly important issue. According to the Durban decision, the liability for this risk could rest with either the buyer of credits (buyerliability) or the seller of credits (seller-liability). In the latter case the host country, in effect, would assume the leakage risk. The experience of afforestation and reforestation projects under the CDM is that a buyer-liability regime may substantially reduce demand for carbon credits generated from CCS projects. This could reduce the efficacy of the CDM, or a similar projectbased crediting system for CCS projects in the developing world. As discussed below, guarantees and insurance instruments, possibly provided by development banks, could create a sellerliability regime.

The CDM, or an equivalent mechanism, might provide an important financial contribution to CCS deployment in developing countries. A recent paper by the World Bank (Kulichenko and Ereira, 2011) estimates that a carbon price signal of between USD 15 and USD 50 per tonne of $\mathrm{CO}_{2}$ could facilitate between 7 and 26 CCS projects in the developing world by 2020, delivering $26 \mathrm{MtCO}_{2}$ to $80 \mathrm{MtCO}_{2}$ of avoided emissions. Most of these projects will likely be in the natural gas processing sector.

\section{Much public sector support to come from developed countries}

Carbon prices alone will not stimulate the optimal level of CCS investment in developed countries in the short and medium term, and the same is true in developing countries. Additional public financing mechanisms are justified. The authors of the World Bank paper (Kulichenko and Ereira, 2011) estimate that realising the goal set out in the IEA CCS Roadmap for deployment in developing countries by 2020, will require an investment of between USD 1 billion and 
USD 2.6 billion per annum beyond that leveraged by the carbon market (USD 8 billion to USD 21 billion over the period 2010-20).

The emerging post-2012 framework for international climate finance flows recognises that a substantial proportion of costs will be met by developed countries. It allows that some of this may be achieved through nationally appropriate mitigation actions (NAMAs), which will outline

Page 36 the costs, emissions reduction and timeframe associated with these actions. These will be matched to offers of support, made available by developed countries through a NAMA registry. These offers of support could cover both capital and operating costs and could take a number of different forms, including building capacity, overcoming financing barriers, reducing the costs of implementing policies (e.g. FITs), and developing and demonstrating advanced technologies that 5are not cost-effective today. ${ }^{13}$

This post-2012 framework is notably different from the carbon market. First, supported NAMAs will produce $\mathrm{GHG}$ emissions reduction that will act as contributions from developing countries in the global effort to control climate change; they will not, however, deliver offsets for developed countries. Second, in most cases, support for NAMAs will begin after developing countries achieve a certain level of emissions reduction with their own resources through business as usual (so-called unilateral actions). Depending on the growth pattern of the developing country, supported NAMAs (e.g. policies, programmes) may produce net reduction in emissions or they may reduce the amount of growth in emissions that would otherwise occur in these countries.

Developed countries will provide support for CCS deployment in developing countries (through NAMAs or other processes) partly for political reasons. However, in the context of CCS, developed countries (and firms domiciled in these countries) can realise some non-political benefits by supporting developing country mitigation efforts:

- introducing CCS to a variety of environments, including in developing countries, may lead to greater learning than regionally concentrated pilots in a few developed countries;

- CCS deployment may be possible at lower cost in the developing world;

- firms domiciled in one country may enhance technology leadership by demonstrating the ability to operate in a range of different locations, laying the groundwork for a strong position in a global CCS market; and

- benefits of reduced climate change damage accrue globally, no matter where $\mathrm{CO}_{2}$ is captured and stored.

Developed countries with the greatest long-term interest in CCS technology may be interested in supporting CCS projects in the developing world in order to facilitate wide-scale adoption. Meadowcroft and Langhelle (2009) identify five motivations for developed-country interest in $\mathrm{CCS}^{14}$

- securing revenues from fossil fuel production;

- consuming fossil fuels to promote economic growth;

- promoting energy security;

\footnotetext{
${ }^{13}$ For more details, see Center for Clean Air Policy (2009).

${ }^{14}$ These motivations relate to the use of CCS to capture emissions from fossil fuel combustion. Somewhat different considerations may apply in relation to the use of CCS to capture emissions from biomass combustion (BECCS), as countries where biomass combustion is already significant (such as Brazil and Colombia) may have a greater interest. Although BECCS (discussed in detail in the next section) is of considerable importance given its potential to generate negative emissions, the analysis here concentrates on conventional use of CCS, reflecting the global significance of fossil fuel combustion.
} 
- promoting regional cohesion; and

- facilitating foreign-policy objectives, such as greater earnings from CCS technology exports.

All else being equal, countries that are more heavily exposed to damages from climate change will be more motivated to explore CCS to reduce this exposure than countries that do not face the same threat. Availability of sufficient storage capacity will also influence the extent to which countries are interested in supporting CCS, although reliable estimates on this remain elusive.

Some of the motivations above can be proxied by various metrics, but others are inherently more qualitative. An analysis of three of these variables for a series of key developed countries (Figure 8) identifies the United States and Australia as two countries with the greatest motivation for CCS, and the most to gain from further supporting CCS projects in the developing world. The proxy for continued revenues from fossil fuel production is proven reserves (ktoe) of coal and gas (shown on the vertical axis); the proxy for continued consumption of fossil fuels to promote growth is emissions of coal and gas per unit of GDP (shown on the horizontal axis); and the proxy for interest in CCS for its contribution to averting climate change is the level of climate vulnerability (Wheeler, 2011) (shown in the bubbles). Countries that are further to the top right and with larger bubbles are those which might be expected to have the greatest interest in CCS, and hence most willing to support CCS in the developing world.

Figure 8 Analysis identifying developed countries most motivated to support CCS in the developing world

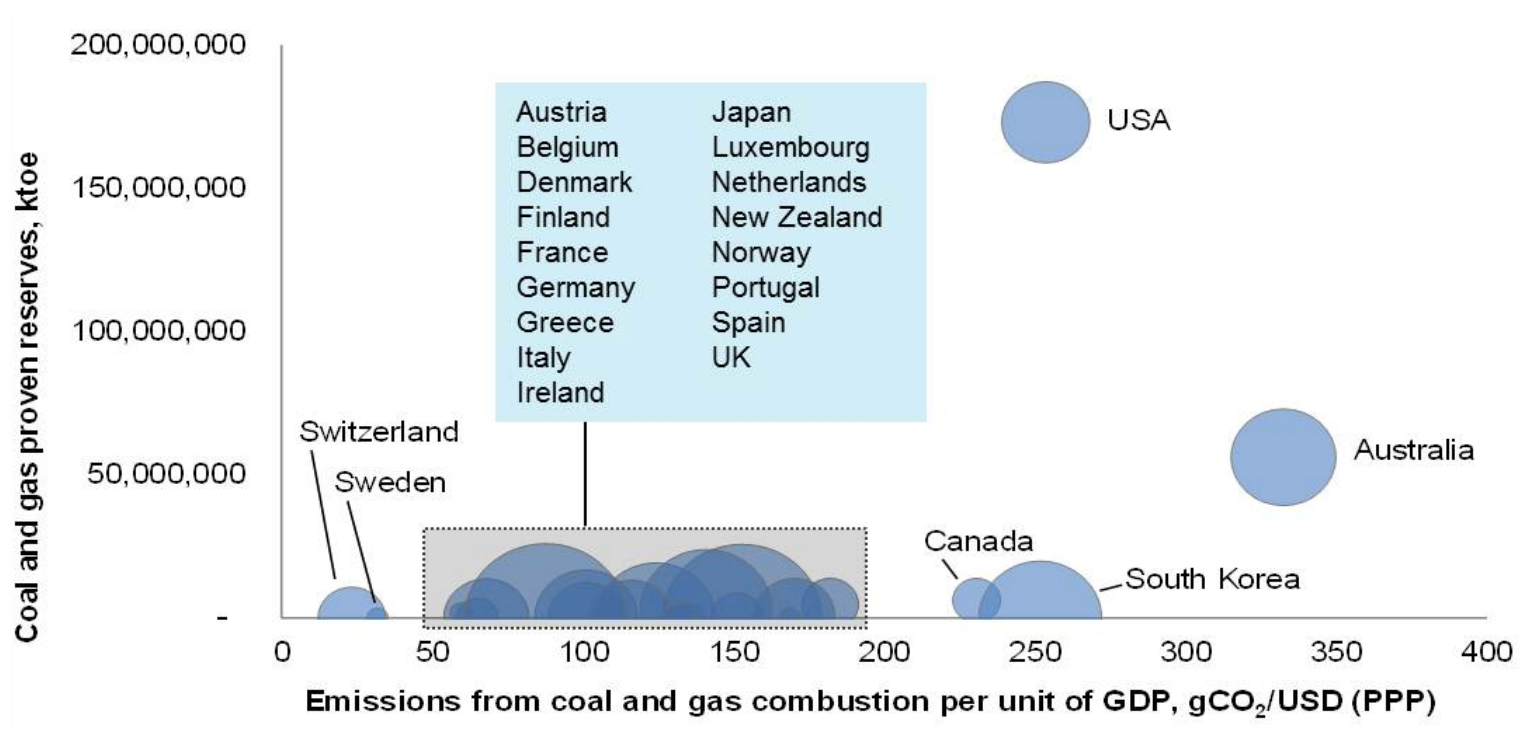

Notes: Focuses on Annex II countries with obligations under the Kyoto Protocol to support developing countries. Size of bubble proportional to potential climate damages.

Sources: Wheeler, 2011 (climate vulnerability); IEA, 2010a and 2010b, and Penn World Tables (emissions from coal and gas combustion per unit of GDP), BP Statistical Review of World Energy, 2010 (coal and gas proven reserves).

A similar analysis (Figure 9) can be used to reveal developing countries that could have the greatest strategic interest in CCS deployment, in many cases supported through developed country finance. This suggests that China, India, Kazakhstan, South Africa, and Uzbekistan (on the basis of its fossil fuel consumption rates) could be some of the most interested countries. 
Figure 9 Analysis to identify developing countries with greatest strategic interested in CCS deployment

Page | 38

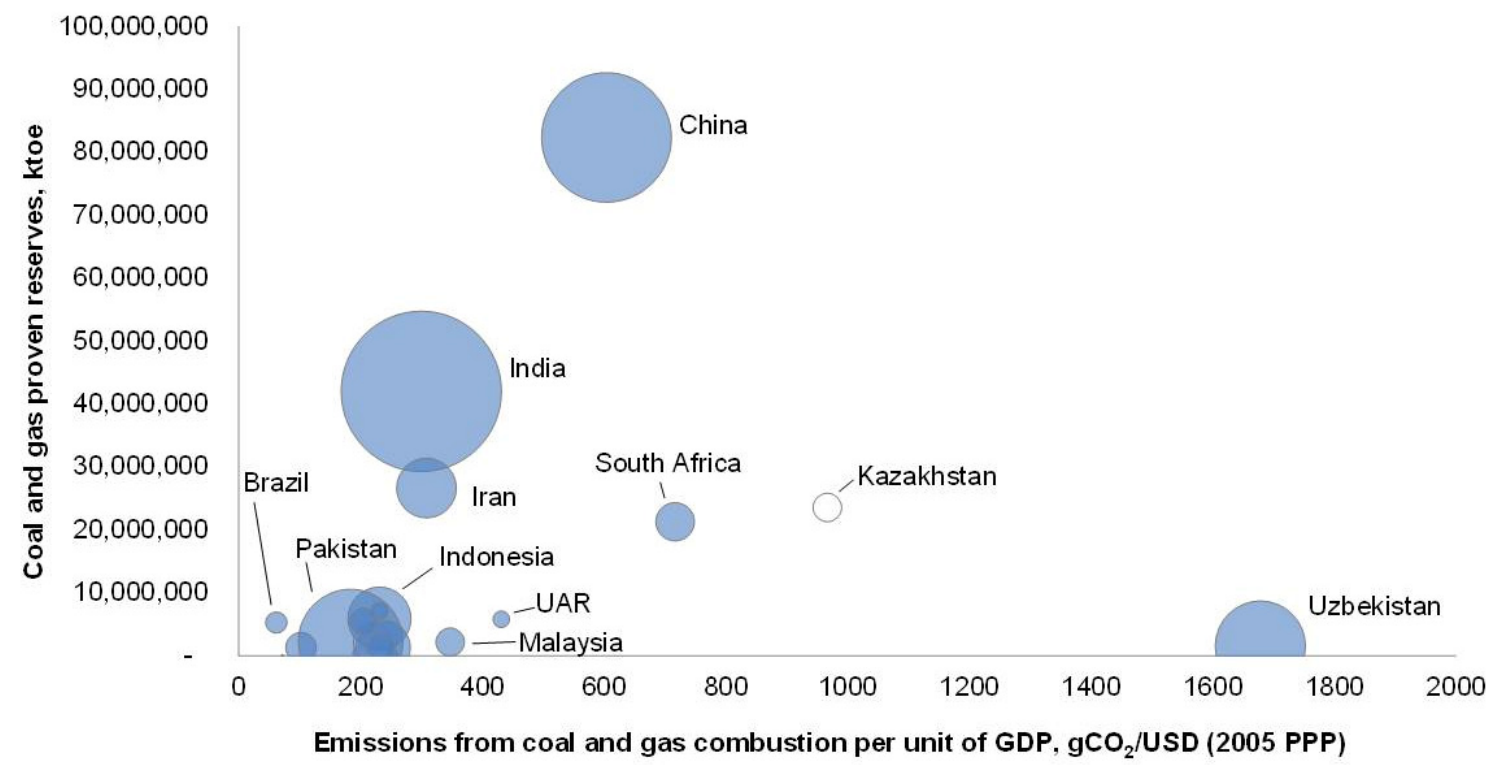

Notes: Only countries with more than 2 quadrillion BTU are included in sample. Size of bubbles proportional to potential climate damages. Kazakhstan is predicted to benefit from climate change, and thus has "a negative size", indicated by shading.

Sources: IEA (2010a and 2010b) (imports, exports, domestic consumption of fossil fuel and of total energy); Wheeler (2011) (climate vulnerability).

\section{Longer public support from developed countries}

CCS technologies used in the developed world are likely to require adaptation for use in the developing world. In such cases, it may be appropriate to subsidise CCS deployment in developing countries for a longer period, to reflect specific benefits acquired from learning how to use CCS technologies in these contexts. This support is likely to be in the form of capital, as it is often difficult for developing countries to credibly commit to long-term multi-year operational support, and they often face greater challenges in raising capital. Also, removal of public support for CCS makes it likely that final product prices will rise, causing additional social concerns in parts of the developing world. ${ }^{15}$

\section{Development banks can help overcome capital market failures}

In some developing countries, the challenges associated with deploying capital due to the uncertainty in CCS technology and policy may be compounded by more general challenges associated with the national investment climate. The risks include currency volatility, transfer restriction, expropriation, war and civil disturbance, and breach of contract. These additional challenges may slow CCS deployment in the developing world, despite the potential to realise both learning benefits and abatement at lower cost. IFIs, such as the World Bank or the Asian Development Bank, have played a role in surmounting these challenges. IFIs could adopt a number of different strategies to support investment in CCS (Box 5).

\footnotetext{
${ }^{15}$ See Annex A for a detailed discussion of cost pass-through.
} 
A common model in IFI engagement is to combine non-concessional loans (financed through the shareholder equity invested in the IFI) with concessional funds (separately financed through grants made by donors, often explicitly earmarked to support particular activities). Non-concessional (commercial) loans help to finance the baseline cost of a project, while concessional loans/grants are used to finance low-carbon aspects. In a recent example of this framework in South Africa, a nonconcessional loan of USD 3.75 billion was used to finance Eskom's Medupi coal-fired power plant. This was supplemented by USD 350 million of concessional finance from the Clean Technology Fund (CTF) towards concentrated solar power (CSP) and wind power. A similar combination could be used to fund CCS-equipped fossil-fuel power plants: non-concessional loans could be issued to fund the power plant and concessional funds to finance the CCS equipment.

The CTF, one of two Climate Investment Funds (CIFs), provides a model for IFI involvement in lowcarbon concessional finance. Approved in 2008, it has to date received pledges of around USD 4.4 billion from developed countries (just over $60 \%$ as grants and the remainder as loans). Its aim is to finance "projects and programs that contribute to demonstration, deployment and transfer of low carbon technologies with a significant potential for long term greenhouse gas emissions savings" (the World Bank, 2008). This is achieved by channelling resources through the World Bank and the various Regional Development Banks (collectively, the Multilateral Development Banks) with the resources then invested, to varying degrees, on concessional terms. The grant element of funds range from $45 \%$ to $75 \%$.

Although the CTF is currently restricted from supporting CCS projects, a similar model could be used for concessional loans/grants to CCS projects. The CTF offers developing countries opportunities to pursue low-carbon development paths according to national priorities, while the involvement of a number of different institutions helps ensure that technologies can be deployed in a variety of different geographies. This may be particularly important for CCS as some learning may be regionspecific. However, concerns have also been raised around some operational aspects of the CTF (and CIFs more generally), particularly related to transparency of decision making (Nakhooda, 2010).

Risk mitigation instruments are an increasingly popular method of supporting low-carbon private sector investment (the CTF can provide some such instruments) and these are likely to also be particularly important for CCS projects. These instruments include political risk insurance from the Multilateral Investment Guarantee Agency (MIGA), which provides insurance against a wide range of non-commercial risks (e.g. transfer restriction, expropriation, war and civil disturbance, and breach of contract for cross-border investment). There has been increasing discussion about extending this insurance against political risk to cover a wider set of policy risks (UNEP, 2009 and Brown and Jacobs, 2011). There may be scope to tailor these instruments to deal with risks unique to CCS, such as longterm environmental liability and stewardship of storage sites. Alternatively, more general loan guarantees (transferring part or all of the risk from the lender onto the loan guarantor, irrespective of the reason for any default) may also play an important role. Some studies suggest that the private sector investment leveraged by these guarantees can be between six times and ten times the value of the guarantee (Brown and Jacobs, 2011).

More innovatively, a complementary model might be to facilitate carbon credit sales from CCS projects through the issue of advance purchase guarantees. IFIs, in conjunction with other public or private sector investors, might agree to buy CCS credits at a predetermined price. The IFI would seek to certify these credits in a post-2012 carbon offset mechanism. In the event that credits were verified, the appreciation in value would be shared between the IFI, investors and the CCS project owners. The IFI here would share in the risk of future carbon offset regulation. By creating a dependable and predictable revenue stream for CCS projects, access to finance might be improved, although it would place a large amount of policy risk on the IFI and would only be effective in cases where projects are fundamentally commercially attractive. It could be modelled on the World Bank's Prototype Carbon Fund (PCF), used in the early 2000s to catalyse the project-based carbon credit market.

In all of these cases, the provision of hard finance is complemented by technical assistance and capacity building covering technical know-how, environment and safety, liability monitoring, and reporting and verification. 


\section{Good case for a dedicated CCS fund (or window in existing fund) administered by IFIs}

In summary, while project- or sector-based crediting mechanisms will provide a carbon price signal that can be expected to generate some CCS projects in the developing world, there is a strong need for further public finance support to meet the goals set out in the IEA CCS Roadmap. Developed countries will have differing levels of motivation to provide such support, with Australia and the United States perhaps standing out as having the strongest interest, while China, India and South Africa could have a strategic interest in receiving such support for CCS. Much of this support will likely be provided as capital which may be best administered and disbursed by larger IFIs, including Multilateral Development Banks.

One institutional framework that could deliver these outcomes is a dedicated CCS fund (or an explicit CCS window within a larger climate fund) with resources provided by developed countries with the greatest interest in CCS. The justification for explicitly separated support for CCS is to ensure that sufficient resources are made available to generate the expected learning from CCS deployment in the developing world - even when it may not represent the most costeffective short-term abatement option. In other words, the same reasoning that justifies CCSspecific instrument support similarly justifies CCS-specific financing support. Almendra et al. (2011) suggest that a figure of around USD 5 billion to USD 8 billion might be appropriate, while the Asian Development Bank has also called for a multi-billion dollar fund. The fund could offer a range of different financing instruments including grants and concession lending, as well as some of the more innovative risk mitigation instruments outlined in Box 5.

Given the experience of the Multilateral Development Banks in providing these instruments, further developed through the CIFs (of which the CTF is especially relevant), some role for these organisations in disbursing these resources appears desirable, although governance structures would require careful consideration. In any case, in light of the substantial investment needs and the leveraging potential of these more innovative instruments, it is better to allow both private sector investors and government access to the resources.

The introduction of some competition in access to these resources (rather than allocating resources according to administrative criteria or on a first-come, first-served basis) would promote value for money in the use of these funds (UNEP and Partners, 2009; Almendra et al., 2011). Careful attention would be needed to ensure that the mechanism supports a sufficient diversity of CCS technologies, in a sufficient number of sectors, to generate the desired learning.

\section{BECCS}

Conventional fossil-fuel CCS can at most realise zero emissions, but BECCS (bioenergy with CCS) can achieve negative emissions. CCS and BECCS are equivalent at the point of fuel transformation and storage, so CCS is likely to receive uniform incentives regardless of the source of the $\mathrm{CO}_{2}$ not released to the atmosphere. In the case of BECCS, an additional incentive is warranted to reflect its potential to deliver negative lifecycle emissions. The additional incentive can be applied the point of biological sequestration, at capture or at storage. 


\section{An extra incentive for BECCS}

BECCS refers to the use of CCS technology to capture emissions from biomass processing or combustion. It can be used in a wide range of contexts, including biomass power plants, combined heat and power plants, flue gas streams from the pulp industry, fermentation in ethanol production, and biogas refining processes (IPCC, 2011). In autumn 2011, one BECCS plant at commercial scale is in operation in the United States with another three projects due to start later (Biorecro, 2011).

Contrary to conventional, fossil-fuel based CCS (or renewable generation technologies), BECCS is capable of achieving negative emissions over its lifecycle. Recent modelling analysis has suggested that, given current trends in emissions, technologies such as BECCS that reduce atmospheric concentrations of $\mathrm{CO}_{2}$, are likely to be crucial in order to reach more ambitious stabilisation targets (Edenhofer et al., 2010). Within a framework aimed at correcting the carbon externality, an extra incentive for BECCS would reflect its higher contribution to abatement.

\section{How BECCS delivers negative emissions}

Conventional CCS can, at most, reduce the rate of increase in atmospheric $\mathrm{CO}_{2}$ concentrations. Over the lifecycle, hydrocarbons are removed from the ground, combusted and then returned underground. Not accounting for associated mining or drilling, transport and refining activities, the best achievable outcome is zero net emissions.

BECCS has the potential to reduce atmospheric GHG concentrations. Assuming the cycle starts with bare ground (rather than established forest), during the production of biomass $\mathrm{CO}_{2}$ is sequestered from the air as the plant grows and stored in solid form as part of the final biomass fuel. At the point that $\mathrm{CO}_{2}$ would otherwise be released to the atmosphere, the emissions are captured and stored underground. Over the lifecycle, the $\mathrm{CO}_{2}$ has been removed from the air and stored in the ground, reducing the overall stock of $\mathrm{CO}_{2}$ in the atmosphere.

A schematic representation comparing lifecycle emissions of conventional CCS and BECCS highlights the conceptual difference between BECCS and conventional CCS, illustrating how BECCS can create negative emissions in a way that conventional CCS cannot (Table 5). For the purposes of this schematic representation, it is assumed that, in the case of BECCS, the amount of $\mathrm{CO}_{2}$ released from fuel transformation and subsequently captured is the same as was biologically absorbed, and that the emissions from fossil fuel combustion and biomass combustion/processing are identical.

Table 5 Comparing lifecycle emissions of conventional CCS and BECCS

\begin{tabular}{l|c|c}
\hline & Conventional CCS & Biomass energy with CCS \\
\hline Biological sequestration & 1 & -1 \\
Fuel transformation & -1 & 1 \\
Capture and storage & 0 & -1 \\
Lifecycle emissions & & -1 \\
\hline
\end{tabular}

Note: These numbers do not represent actual emissions and do not reflect a number of lifecycle emissions associated with BECCS, such as direct and indirect land-use change. 


\section{Implementing the BECCS incentive}

CCS and BECCS are equivalent at the point at which the $\mathrm{CO}_{2}$ would otherwise be released into the atmosphere. A distinct set of incentives applies to capture and storage, independent of the source of the $\mathrm{CO}_{2}$ emissions. The additional incentive for BECCS - required to reflect negative Page | 42 lifecycle emissions - is applied on top of this. The additional incentive can be applied at biological sequestration, at capture or at storage.

\section{One set of incentives for capture and storage for both fossil fuels and biomass}

At the point of fuel transformation, both fossil fuels and biomass would normally release greenhouse gases. Although it may use different technologies, capture equipment would fulfil the same function on each fuel: preventing emissions from reaching the atmosphere. This may be reflected in one set of incentives for capture and storage technology - independent of the fuel on which the equipment ultimately operates. BECCS could be eligible for all incentives that apply to conventional CCS. ${ }^{16}$

\section{Three options for when to apply the additional incentive for BECCS}

To reflect the negative lifecycle emissions that BECCS is capable of achieving, an additional incentive could be applied to biological sequestration, or capture, or storage (Figure 10).

Figure 10 BECCS lifecycle emissions can be recognised at one of three points

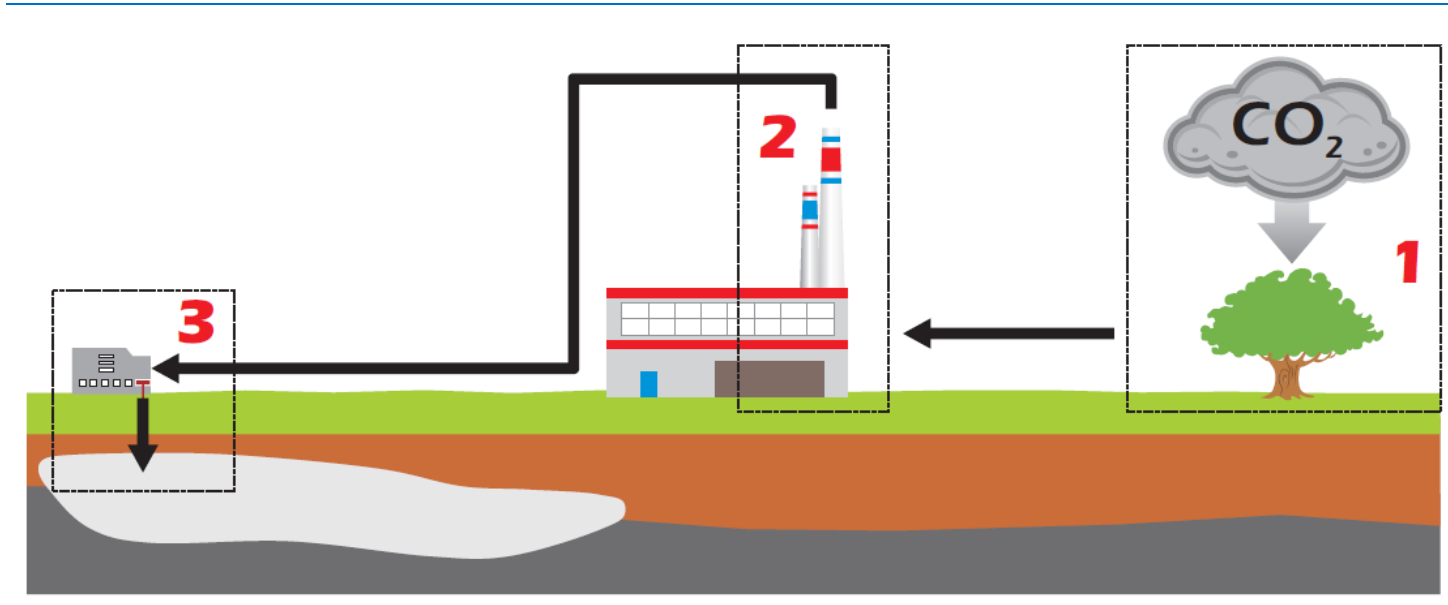

Notes: 1. Biological sequestration. 2. Capture. 3. Storage.

There are advantages and disadvantages to each point of application (Table 6). The advantage for policymakers of providing the extra incentive at capture is that they can use the same basic administrative infrastructure as for incentivising CCS from fossil feedstock (Azar et al., 2006). However, some countries may wish to put the BECCS incentive at biological sequestration if this fits better with their biomass policies.

\footnotetext{
${ }^{16}$ See Groenenberg and Dixon (2012) for a review of the status of BECCS within the European Emission Trading Scheme.
} 
Table 6 Advantages and disadvantages of BECCS incentive options

\begin{tabular}{|c|c|c|c|}
\hline Point of application & $\begin{array}{c}\text { Example of } \\
\text { implementation }\end{array}$ & Advantages & Drawbacks \\
\hline $\begin{array}{l}\text { 1. Biological } \\
\text { sequestration }\end{array}$ & $\begin{array}{l}\text { Credits provided for } \\
\text { afforestation/reforestation } \\
\text { under the Kyoto Protocol } \\
\text { and credits for biological } \\
\text { sequestration in New } \\
\text { Zealand ETS. }\end{array}$ & $\begin{array}{l}\text { Does not discriminate } \\
\text { between different } \\
\text { downstream usages of } \\
\text { biomass. } \\
\text { Encourages innovation in the } \\
\text { production of biomass. } \\
\text { Could be extended to other } \\
\text { sequestration technologies in } \\
\text { future. }\end{array}$ & $\begin{array}{l}\text { Requires good scientific } \\
\text { understanding of sequestration } \\
\text { process, including LULUCF and } \\
\text { ILUC impacts. } \\
\text { Implementation may be costly if } \\
\text { covering all producers of biomass. }\end{array}$ \\
\hline $\begin{array}{l}\text { 2. Fuel } \\
\text { transformation } \\
\text { and capture }\end{array}$ & $\begin{array}{l}\text { BECCS receives a } \\
\text { multiple of the general } \\
\text { operating support given to } \\
\text { capture equipment. }\end{array}$ & $\begin{array}{l}\text { Easy to implement using the } \\
\text { same administrative } \\
\text { infrastructure as normal } \\
\text { CCS. }\end{array}$ & $\begin{array}{l}\text { Calibrating support to reflect the } \\
\text { additional abatement may be a } \\
\text { small challenge. } \\
\text { Risk of supporting unsustainable } \\
\text { biomass. }\end{array}$ \\
\hline 3. Storage & $\begin{array}{l}\text { Carbon from biomass } \\
\text { combustion eligible for } \\
\text { discounted storage costs. }\end{array}$ & $\begin{array}{l}\text { Encourages delivery of } \\
\text { captured carbon all the way } \\
\text { to storage. }\end{array}$ & $\begin{array}{l}\text { Similar to (2) } \\
\text { Careful accounting may be } \\
\text { necessary to prevent cheating, for } \\
\text { example through re-labelling. }\end{array}$ \\
\hline
\end{tabular}

Abbreviations: LULUCF: land use, land-use change and forestry; ILUC: indirect land-use change

\section{More research needed on accounting of BECCS}

The idea of BECCS has been considered for more than a decade (Obersteiner et al., 2001), and some of the challenges of how to account for it have been resolved. For the power sector, some overall assessments have been produced (Uddin and Barreto 2008), taking into account emissions from harvesting, transporting and processing. Transport, storage and further factors continue to be investigated in depth (Broek et al., 2008).

However, uncertainties remain. In particular, the cultivation of biomass may lead to deforestation or other forms of land-use change in the immediate physical location where the biomass is cultivated (direct land-use change), but also in physically more distant locations (indirect land-use change). ${ }^{17}$ In the latter case, this may be difficult to attribute and monitor, although it may compromise the lifecycle emissions savings that BECCS could achieve. Estimates of BECCS total lifecycle emissions (including activities required to cultivate, harvest, transport and process combustion-ready biomass), have not yet been conclusively ascertained, ${ }^{18}$ but progress has been made on understanding the impact of indirect land-use change. ${ }^{19} \mathrm{~A}$ solid scientific understanding of these may be a crucial pre-condition for well-calibrated BECCS support.

Interestingly, incentive policies themselves could be designed to elicit this information. DeCicco (2009) proposes using a conservative default emission factor, with scope for producers and users of biomass to demonstrate the superior performance of their particular biomass product chain; the costs of attempting to demonstrate this superior performance would only be incurred by

\footnotetext{
17 Rhodes and Keith (2008), for example, investigate the trade-off between food production and biomass for energy production.

${ }^{18}$ For instance, Chum et al. (2011) report that, even excluding the impact of land-use change: "review studies report varying estimates of GHG emissions and a wide range of results have been reported for the same bioenergy options, even when temporal and spatial considerations are constant".

${ }^{19}$ Havlik et al. (2010) give an assessment of the so-called ILUC effect associated with biofuel targets, using a bottom-up partial equilibrium model which integrates the agricultural, forestry and bioenergy sectors.
} 
those who had a good chance of success. Such process could also then lead to additional incentive provided for biomass that achieves superior performance.

\section{Incentives for BECCS require appropriate emissions accounting}

Emissions from bioenergy may currently be under-reported in Annex I countries -- not due to a lack of scientific expertise, but due to current accounting policy. An IEA Working Paper (IEA, 2011) examines the implications for emissions accounting when CCS is used in conjunction with biomass. When biomass is combusted, emissions are given as zero in the energy sector, since the released $\mathrm{CO}_{2}$ was previously removed from the atmosphere during cultivation of the biomass, releasing no new $\mathrm{CO}_{2}$ into the atmosphere. Processing and other lifecycle emissions are accounted for in the LULUCF category, and are hence not attributed to combustion. However, in the first commitment period of the Kyoto Protocol, accounting for emissions and removals from land management activities in the LULUCF sector is voluntary for Annex I countries. ${ }^{20}$ Where LULUCF emissions are incompletely reported or not reported at all, biomass energy can erroneously appear to cause zero emissions over its lifecycle.

In order to properly assess the net impact of BECCS on emissions, it is crucial to have a thorough scientific understanding of the lifecycle emissions of BECCS, and to update accounting policy to ensure, to the best extent possible, accurate and mandatory reporting. This should be a prerequisite for supporting and incentivising BECCS as a carbon reduction technology.

\section{Conclusions}

This report points out the benefits of a balance between policy certainty and flexibility as CCS develops. This approach recognises the advantage to governments of having flexibility to respond to new information and the benefits to investors of certainty in financial performance. To achieve this balance, the report proposes a policy framework where the policy mix would evolve over time, with explicit phases of policy punctuated by break points or "gateways". These gateways would allow a smooth transition between current policies, which focus on learning how to reduce costs of the technology, and future policies, which will offer incentives to stimulate take-up of CCS wherever it is cost-effective to do so.

Markets can be made to function better, in particular to promote learning through the early period of deployment. This learning has some characteristics of a public good - a feature which justifies governments in intervening to secure it. In developed countries, after the current phase of grant-based support expires, quantity instruments may be most effective in securing learning. Where institutional arrangements allow, a premium FIT (i.e. a fixed increase to the price of products supplied from plants where CCS is deployed), may be an effective alternative. In developing countries, the same findings hold, but there may be a case for longer retention of grant-based policies or other support for financing CCS investment.

Given that learning may occur in any location, an international policy framework to promote learning is desirable. Learning can be delivered most easily in the power-generation sector, which in many countries is able to absorb costs with less distortion of international competition than trade-exposed sectors -although a proportion of costs will still be passed on to trade-exposed consumers. Other sectors, which might adopt the technology early because it is less costly to do

\footnotetext{
${ }^{20}$ Currently it is mandatory to account for afforestation, reforestation, and deforestation, while it is voluntary to account for forest management, grazing land management, cropland management and revegetation.
} 
so, include industries where a $\mathrm{CO}_{2}$ stream is created as a result of existing productions processes (e.g. natural gas processing, sugar fermentation and some chemical industries). The programme may also be introduced first in low-cost locations, i.e. those where technical expertise and the supply chain are available, and contract and policy risk - and energy prices - are low. Learning support could be funded mostly, or indeed entirely, by developed countries.

At the end of the main period of learning, once a limited programme of deployment has been completed, the focus will turn from learning about CCS technology, to providing incentives for cost-effective abatement. If CCS costs have fallen sufficiently the optimal approach will be through a broad multi-sector or economy-wide carbon price. This will encourage CCS only insofar as it is less costly than the carbon price, where the price may be set either directly as a tax, or indirectly in an emissions-trading scheme. If CCS costs have not fallen substantially, but no other alternative technologies have emerged that offer the same abatement potential, then narrower, sector-specific policies to support CCS, such as emissions performance standards, may be preferable.

From the perspective of $\mathrm{CO}_{2}$ network development, there are benefits from greater certainty in demand, but this may carry little weight because a network would be a relatively small component of the cost of the entire CCS system; and it is possible to build a network incrementally, from bilateral connections and clusters, by adding links to make an integrated system. The more important issues for network provision are likely to be coordination between prospective users, the oversight of access conditions, and pricing.

Where emissions from bioenergy use are captured and stored, the amount of $\mathrm{CO}_{2}$ in the atmosphere is reduced. This could be rewarded through incentives to growers or harvesters, or through additional incentives at the capture plant or $\mathrm{CO}_{2}$ store. Each policy option has advantages and drawbacks, with ease of implementation and support of biomass policies being key considerations.

CCS technology is of fundamental importance in the effort to reduce global emissions and avert dangerous effects of climate change. It will need to evolve from a largely untested technology to deployment at scale around the world, possibly at unprecedented speed. Policy for CCS needs to be flexible, yet able to provide investors with enough certainty to make substantial financial commitments. Balancing these competing interests will be a substantial challenge. 


\section{References}

Abadie, L. and J. Chamarro (2008), "European $\mathrm{CO}_{2}$ prices and carbon capture investments", Energy Economics, 30 (2008), pp. 2992-3015.

Almendra, F., L. West and L. Zheng (2011), CCS Demonstration in Developing Countries: Priorities for a Financing Mechanism for Carbon Dioxide Capture and Storage, World Resources Institute Working Paper, Washington, DC, USA.

Azar, C. et al. (2006), "Carbon capture and storage from fossil fuels and biomass - costs and potential role in stabilizing the atmosphere", Climatic Change, (1-3) 74, pp. 47-79.

Armstrong, R. (2011), personal communication.

Biorecro (2011), Global status of BECCS projects 2010, Biorecro AB, Stockholm, Sweden.

Broek, van den M., A. Faaij, and W. Turkenburg (2008), "Planning for an electricity sector with carbon capture and storage - Case of the Netherlands", Greenhouse Gas Control 2 (2008), pp. 105-129.

Brown, J. and M. Jacobs (2011), Leveraging private sector investment: the role of public sector climate finance, ODI Background Note, Overseas Development Institute, London, UK.

Bundesverband der Deutschen Zementindustrie e.V. (2011), Zahlen und Daten 2010-2011, Berlin, Germany.

Butler, L. and K. Neuhoff (2008), "Comparison of feed-in tariff, quota and auction mechanisms to support wind power development", Renewable Energy, 33 (8), pp. 1854-1867.

Climate Action Network (2011a), LULUCF Briefing - Bioenergy, www.climatenetwork.org/publication/lulucf-briefing-bioenergy.

Carley, S (2009), "State renewable energy electricity policies: an empirical evaluation of effectiveness", Energy Policy, 37:8, pp. 3071-3081.

Center for Clean Air Policy (2009) Nationally Appropriate Mitigation Actions by developing countries: architecture and key issues, Center for Clean Air Policy, Washington, DC, USA.

Centraal Bureau voor de Statistiek, Statline database, http://statline.cbs.nl/StatWeb/?LA=en.

Chum, H., et al. (2011), "Bioenergy", in O. Edenhofer, et al. (eds.), IPCC Special Report on Renewable Energy Sources and Climate Change Mitigation, Cambridge University Press, Cambridge, United Kingdom and New York, NY, USA.

Climate Funds Update, Clean Technology Fund, www.climatefundsupdate.org/listing/clean-technologyfund, accessed July 2011.

Department of Climate Change and Energy Efficiency (DCC) (2011), www.cleanenergyfuture.gov.au, accessed 14 November 2011.

DeCicco, J.M. (2009), Addressing Biofuel GHG Emissions in the Context of a Fossil Based Carbon Cap. Discussion Paper, University of Michigan, School of Natural Resources and Environment, Ann Arbor, MI, USA.

Department of Energy and Climate Change (DECC) (2010), Optimization of $\mathrm{CO}_{2}$ Storage in $\mathrm{CO}_{2}$ Enhance Oil Recovery Projects, Advanced Resources International and Melzer Consulting.

DECC (2011a) Electricity Market Reform White Paper 2011, London, UK.

DECC (2011b) Digest of United Kingdom energy statistics (DUKES), www.decc.gov.uk/en/content/cms/statistics/publications/dukes/dukes.aspx. 
Department of Energy (DoE) (2008), DoE Announces Solicitation for \$8.0 Billion in Loan Guarantees, 22 September 2008, Washington, DC, USA.

DoE (2009), Financial Assistance Funding Opportunity Announcement - Funding Opportunity Number: DEFOA-0000015.

DoE (2011a), Recovery Act - Clean Coal Power Initiative Round III, www.fossil.energy.gov/recovery/projects/ccpi.html.

DoE (2011b), FutureGen 2.0, www.fossil.energy.gov/programs/powersystems/futuregen/index.html.

DoE (2011c) Carbon Capture and Storage from Industrial Sources, www.fossil.energy.gov/programs/sequestration/industrial/industrial_ccs.html.

DESTATIS Statistisches Bundesamt (2010), Statistisches Jahrbuch 2010, Wiesbaden, Germany.

Edenhofer, E., et al. (2010), "The economics of low stabilization: model comparison of mitigation strategies and costs", The Energy Journal, 31 (Special Issue 1), pp. 11-48.

EEF (2010), UK Steel Key Statistics 2010, London, UK.

ERM (2009), Financial Support Mechanisms for $\mathrm{CO}_{2}$ capture and storage, $\mathrm{CO}_{2}$ Capture Project, www.co2captureproject.org.

European Union Emission Trading System, Community Independent Transaction Log, accessed at http://dataservice.eea.europa.eu/PivotApp/pivot.aspx?pivotid=473.

Fankhauser, S., C. Hepburn and J. Park (2011), Combining Multiple Climate Policy Instruments: How not to do it, Centre for Climate Change Economics and Policy Working Paper No. 48., London, UK.

Finon, D. (2010), Efficiency of Policy Choices for the Deployment of Large Scale Low-Carbon Technologies: the Case of CCS, Laboratoire d'Analyse Économique des Réseaux et des Systèmes Energétiques, Working Paper No. 27, Paris, France.

Fischer, C. and R. Newell (2008), "Environmental and Technology Policies for Climate Mitigation”, Journal of Environmental Economics and Management, 55 (2), pp. 142-62.

Global Carbon Capture and Storage Institute (2009), Country Studies - The United States of America, Canberra, Australia.

Global Carbon Capture and Storage Institute (2011), The Global Status of CCS, Canberra, Australia.

Groenenberg, H., and T. Dixon (2012), Using carbon markets to advance negative emissions from biomass and CCS, to appear in Energy Procedia.

Hamilton, K. (2009), Unlocking Finance for Clean Energy: the Need for 'Investment Grade' Policy, Chatham House, London, UK.

Havlik, P. et al. (2010), Global Land-Use Implications of First and Second Generation Biofuel Targets, Energy Policy: article in press.

Helm, D., C. Hepburn, R. Mash (2003), “Credible carbon policy”, Oxford Review of Economic Policy, 19:3, pp. 438-450.

Hepburn, C. (2006), "Regulation by prices, quantities or both: a review of instrument choice", Oxford Review of Economic Policy, 22 (2), pp. 226-247.

Illinois General Assembly (2009) Clean Coal Portfolio Standard Law, Public Act 095-1027.

Intergovernmental Panel on Climate Change (IPCC) (2005), Special Report on Carbon Dioxide Capture and Storage - Summary for Policy Makers [?]

IPCC (2011), Special Report on Renewable Energy Sources and Climate Change Mitigation - Summary for Policy Makers, Cambridge University Press, Cambridge, UK and New York, NY, USA. 
International Energy Agency (IEA) (2008), Deploying Renewables: Principles for Effective Policies, OECD/IEA, Paris, France.

IEA (2008), Carbon Dioxide Capture and Storage in the Clean Development Mechanism: Assessing Market Effects of Inclusion, IEA Greenhouse Gas R\&D Programme, OECD/IEA, Paris, France.

IEA (2009), Technology Roadmap - Carbon capture and storage, OECD/IEA, Paris, France.

Page $\mid 48$

IEA and Carbon Sequestration Leadership Forum (2010), Carbon Capture and Storage - Progress and Next Steps, OECD/IEA, Paris, France.

IEA (2010a), Energy Technology Perspectives 2010, OECD/IEA, Paris, France.

IEA (2010b), Energy Balances of OECD Countries, OECD/IEA, Paris, France.

IEA (2010c), Energy Balances of Non-OECD Countries, OECD/IEA, Paris, France.

IEA (2011), BECCS: Aspects of Reporting and Accounting under the UNFCCC and the Kyoto Protocol, OECD/IEA, Paris, France.

Kulichencko, N. and E. Ereira (2011), Carbon Capture and Storage in Developing Countries: a Perspective on Barriers to Deployment, World Bank, Washington, DC, USA.

Laing, T. and M. Grubb (2010), The Impact of Instrument Choice on Investment in Abatement Technologies: A Case Study of Tax Versus Trade Incentive for CCS and Biomass for Electricity, University of Cambridge Electricity Policy Research Group, Cambridge, UK.

Leach, A., C. Mason and K. Veld (2009), Co-Optimization of Enhanced Oil Recovery and Carbon Sequestration, NBER Working Paper, Cambridge, MA, USA.

Lipp, J. (2007), "Lessons for effective renewable electricity policy from Denmark, Germany and the UK", Energy Policy, 35 (11), pp. 5481-5496.

MITEI (Massachusetts Institute of Technology Energy Initiative) (2010), Role of Enhanced Oil Recovery in Accelerating the Deployment of Carbon Capture and Sequestration, Cambridge, MA, USA.

McKibben, W. and P. Wilcoxen, P. (2007), "A credible foundation for long-term international cooperation on climate change", in J. Aldy and R. Stavins (eds.) (2007), Architectures for Agreement, Cambridge University Press, New York, NY, USA.

Meadowcroft, J and O. Langhelle (eds.) (2009), Caching the Carbon: The Politics and Policy of Carbon Capture and Storage, Edward Elgar Publishing, Cheltenham, UK and Northampton, MA, USA.

Mineralölwirtschaftsverband e.V. (2011), Mineralölstatistik, Berlin, Germany.

Mineral Products Association (2010), Quarterly Cementitious, London, England.

Nakhooda, S. (2010), Getting to work: a review of the operations of the Clean Technology Fund, World Resources Institute Working Paper, Washington, DC, USA.

Newbery, D. et al. (2009), Carbon Capture and Storage: Analysis of Incentives and Rules in a European Repeated Game Situation, Electricity Policy Research Group, University of Cambridge, Cambridge, UK.

Norsk Petroleuminstitutt, Salk av oljeprodukter, www.np.no/salgsstatistikk/.

Obersteiner, M. et al. (2001), Managing Climate Risk, Interim Report, International Institute for Applied Systems Analysis, Laxenburg, Austria.

Philibert, C. (2011), Interactions of Policies for Renewable Energy and Climate, IEA Working Paper, OECD/IEA, Paris, France.

Rhodes, S., and D. Keith (2008), "Biomass with capture: negative emissions within social and environmental constraints: an editorial comment", Climatic Change, 87, pp. 321-328.

SSB Statistics Norway, Statistikkbanken, http://statbank.ssb.no/statistikkbanken/. 
Seebregts, A. et al. (2011), Policy Instruments for advancing CCS in Dutch power generation, ECN Policy Studies, Petten, Netherlands.

Stechow, von C. and P. Watson (2011), "Policy incentives for carbon capture and storage technologies in Europe: A qualitative multi-criteria analysis", Global Environmental Change, 21, pp. 346-357.

Tenaska (2009), Tenaska's Taylorville Energy Center Selected By U.S. DOE For Loan Guarantee Program; Illinois Electric Ratepayers Could Save Up To \$60 Million Per Year With \$2.5 Billion Guarantee, www.tenaska.com/news/tem.aspx?id=62.

Uddin, S.N. and L. Barreto (2008), "Biomass-fired cogeneration systems with $\mathrm{CO}_{2}$ capture and storage", Renewable Energy, (6) 32, pp. 1006-1019.

UNEP \& partners (2009), Catalysing low-carbon growth in developing economies: public finance mechanisms to scale-up private sector investment in climate solutions, UNEP, Nairobi, Kenya.

Vereniging Nederlandse Petroleum Industrie (2010), Productie Nederlandse Raffinaderijen, The Hague, Netherlands.

Vivid Economics (2010), Advanced Market Commitments for low-carbon development: an economic assessment, London, UK.

Weitzman, M (1974), "Prices versus Quantities”, The Review of Economic Studies, 41:4, pp. 477-491.

Wheeler, D. (2011), Quantifying Vulnerability to Climate Change: Implications for Adaptation Assistance, CGD Working Paper 240, Center for Global Development, Washington, DC, USA.

The World Bank (2008), Q \& A: Climate Investment Funds (1 July, 2008), World Bank, Washington, DC, USA.

The World Bank, World Integrated Trade Solution Database, http://wits.worldbank.org/wits/. 


\section{Annex A: cost pass-through}

Market and regulatory characteristics determine how costs are allocated between firms and consumers. CCS incentive mechanisms may place the costs and risks of CCS deployment on the private sector (firms and/or consumers) or on the public sector. In the case of the private sector, market and regulatory characteristics determine where the costs of policies ultimately fall.

In discussing the final cost incidence, it is helpful to distinguish between electricity markets (where storage is very difficult and where regulation is often prevalent) and industrial sectors. It is also important to distinguish between the higher marginal costs of CCS operation (the cost of producing each additional unit of output) from the fixed (mainly investment) costs of a capture and storage unit.

\section{Electricity markets}

In a competitive wholesale electricity market, prices reflect the marginal costs of the most costly installation producing electricity at that point in time. This plant is known as the marginal plant. The remaining plants receive a price in excess of their marginal costs. These are known as inframarginal plants.

In most electricity markets, the rate at which the higher marginal costs of CCS are passed on into wholesale prices depends on whether CCS is installed on the marginal plant. If CCS is installed on the marginal plant, then the additional marginal costs of CCS will be reflected in a price increase. CCS may change the identity of the marginal plant. The ordering of plants from lowest cost to highest cost (the merit order) may change when the costs of production of some plants increase. What matters is whether CCS is installed on the marginal plant as defined in the new order.

Fixed costs are typically recovered through infra-marginal rents: the difference between prices and marginal costs received by all units other than the marginal plant. If these rents are sufficient to cover the additional fixed costs of the CCS operation, then the investment will proceed and the higher fixed costs will not affect wholesale prices. Otherwise, capacity would have to exit or not enter as quickly, leading to an increase in prices and infra-marginal rents, allowing the additional fixed costs to be recovered (see Figure 11).

Regulation might alter these dynamics. For instance, it may allow the costs incurred by the plant(s) installing CCS to be shared across most or all companies in the sector (at which point they will be passed through) or to be directly identified as an additional component when calculating consumer bills. This is, for instance, how additional costs of FITs to support renewable electricity generation are often allocated. Alternatively, regulation may prevent any pass-through of higher costs into prices, as is the case in some developing countries. In such cases, costs would either be met out of the rents that the company was previously making or through some form of implicit or explicit subsidy support from government.

If CCS is a cost-reducing investment, brought about by high carbon prices, then these dynamics reverse. In this case, CCS reduces a plant's marginal costs. However, the logic as to whether consumers benefit from this cost reduction is the same: if the marginal plant has lower marginal costs after the installation of CCS (recognising that the identity of the marginal plant itself may change), then consumers will see a reduction in prices. Otherwise the benefits of cost savings will accrue to producers. If entry becomes more attractive as a result of the installation of CCS, then this will stimulate longer-term price reductions. 


\section{Industrial settings}

In industrial settings, prices are typically determined by the collection of decisions each individual firm makes about output or production. In turn, these supply decisions depend mainly on the marginal costs of production: firms with lower marginal costs will find it profitable to produce more than firms with higher marginal costs.

The most important factor determining whether or not changes in marginal costs are ultimately reflected in prices is the proportion of the market affected by the cost change. For instance, where CCS increases marginal costs:

- If many firms are affected by higher marginal costs, then all firms cut back on production and the reduction in supply causes prices to rise. The result is that most of the marginal cost increase is passed through.

- If only a few firms are affected by higher marginal costs, then the cut back in production either makes little difference to total supply or, to the extent it does, the resulting price increase stimulates firms whose costs have not increased to raise production levels, thereby depressing prices. In either case, prices do not ultimately rise significantly and there is limited pass-through of the higher marginal costs.

The logic is reversed in cases where CCS is an investment to reduce costs (i.e. where CCS is incentivised by high carbon prices):

- if most firms reduce their costs by installing CCS, then these marginal cost reductions will be reflected in prices.

- if only a few firms benefit from lower costs then these firms will keep the benefits.

A number of other factors could affect the extent to which higher marginal costs get passed through. These include the price elasticity of demand (if demand is more sensitive to prices, then cost pass-through may be lower) and the intensity of competition provided by firms not affected by the cost increase (if these firms do not compete intensely, then cost pass-through may be higher).

Finally, the higher fixed costs of a CCS plant may only affect prices if the higher fixed costs cause firms to exit the market. Otherwise, the additional fixed costs will be absorbed by firms.

\section{Carbon leakage}

A consequence of the inability to pass through higher marginal costs of CCS is the risk of carbon leakage. As explained above, if costs fall on some firms but not others, production may shift from firms where CCS has been installed to where it has not. The result would be lower environmental gain. Therefore, when assessing whether or not to impose additional costs relating to CCS deployment on industrial sectors, it is appropriate to assess whether the firms face significant competition from locations that are not placing similar obligations on firms. 
Figure 11 Factors influencing cost pass-through in different markets

Page | 52

If higher fixed costs not
covered then capacity will
exit the market (not enter
as quickly) allowing larger
infra-marginal rents until
fixed costs are also
covered

In the short run, prices
are determined by

marginal costs i.e. the

additional costs

associated with producing

another unit of output

If higher fixed costs not covered

then firms will exit the market

allowing remaining firms to price

further above marginal costs

until equilibrium reached with

costs covered

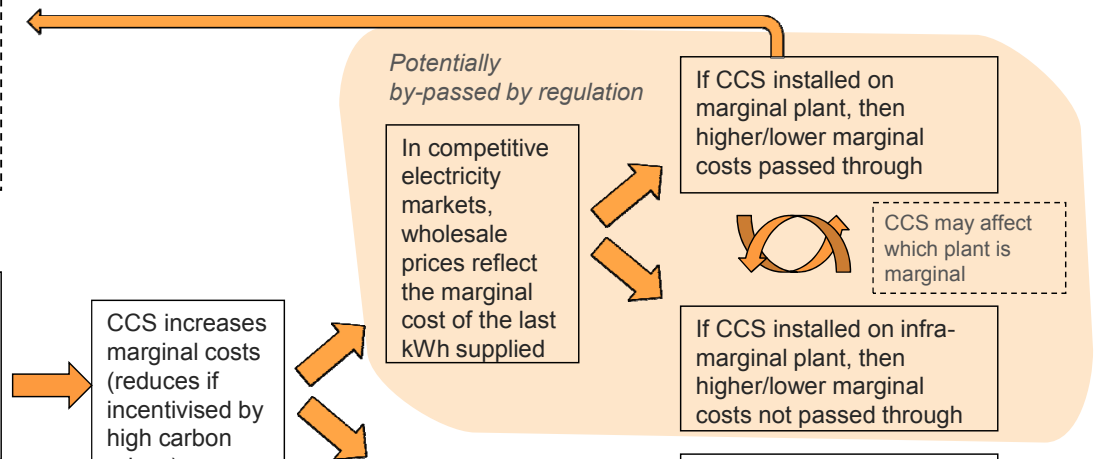

prices)

In less competitive markets, prices reflect output

decisions of all firms.

Output decisions

determined by costs
If most firms in market

face higher costs, then

costs passed through to

prices

If most firms in market do

not face higher costs, then costs not passed through 


\section{iea}

\section{International Energy Agency}
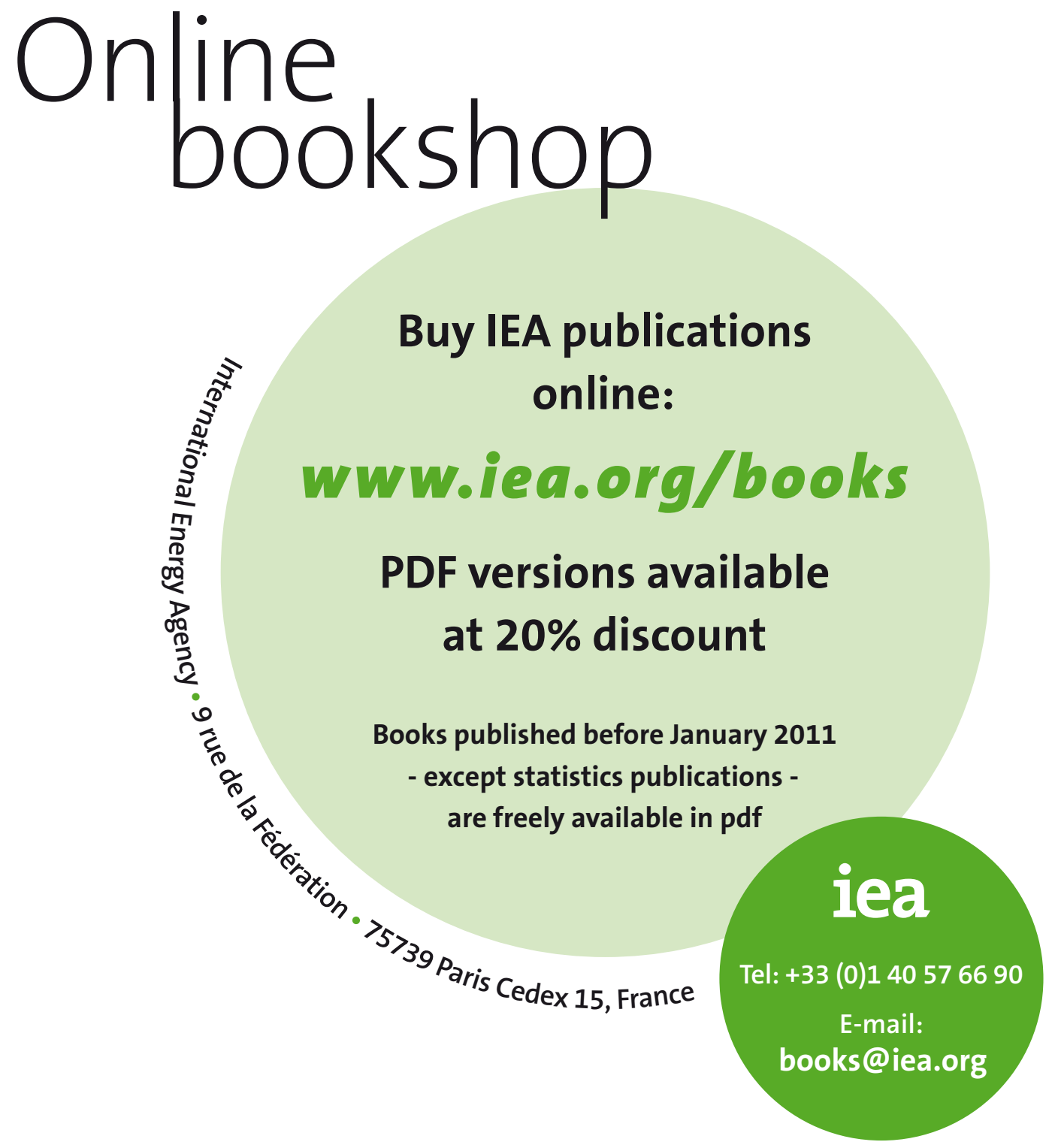
